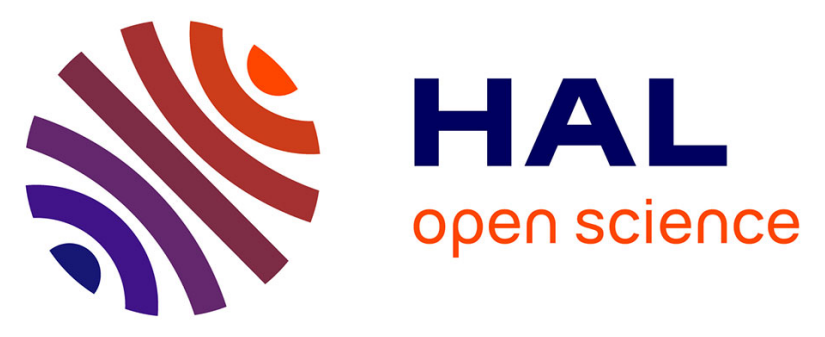

\title{
Self-Assembled Dichroic Plasmonic Nitride Nanostructures with Broken Centrosymmetry for Second Harmonic Generation
}

D. Babonneau, S. Camelio, G. Abadias, D. Christofilos, J. Arvanitidis, S. Psilodimitrakopoulos, G. M Maragkakis, E. Stratakis, N. Kalfagiannis, P. Patsalas

\section{To cite this version:}

D. Babonneau, S. Camelio, G. Abadias, D. Christofilos, J. Arvanitidis, et al.. Self-Assembled Dichroic Plasmonic Nitride Nanostructures with Broken Centrosymmetry for Second Harmonic Generation. ACS Applied Nano Materials, 2021, 4 (9), pp.8789-8800. 10.1021/acsanm.1c01442 . hal-03357416

\author{
HAL Id: hal-03357416 \\ https://hal.science/hal-03357416
}

Submitted on 28 Sep 2021

HAL is a multi-disciplinary open access archive for the deposit and dissemination of scientific research documents, whether they are published or not. The documents may come from teaching and research institutions in France or abroad, or from public or private research centers.
L'archive ouverte pluridisciplinaire HAL, est destinée au dépôt et à la diffusion de documents scientifiques de niveau recherche, publiés ou non, émanant des établissements d'enseignement et de recherche français ou étrangers, des laboratoires publics ou privés. 


\section{Self-Assembled Dichroic Plasmonic Nitride}

\section{Nanostructures with Broken Centrosymmetry}

\section{for Second Harmonic Generation}

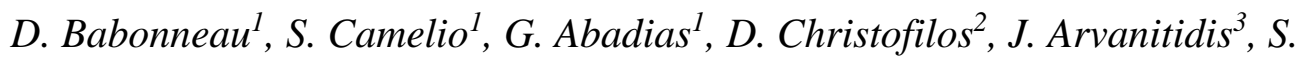

Psilodimitrakopoulos ${ }^{4}$, G.M. Maragkakis ${ }^{4}$, E. Stratakis $^{4}$, N. Kalfagiannis ${ }^{5}$, P.

Patsalas $^{1,3, *}$

${ }^{1}$ Institut Pprime, UPR 3346 CNRS-Université de Poitiers-ENSMA, Département

Physique et Mécanique des Matériaux, 86073 Poitiers, France

${ }^{2}$ Aristotle University of Thessaloniki, Faculty of Engineering, School of Chemical

Engineering and Physics Laboratory, 54124 Thessaloniki, Greece

${ }^{3}$ Aristotle University of Thessaloniki, Department of Physics, 54124 Thessaloniki,

Greece

${ }^{4}$ Institute of Electronic Structure and Laser, Foundation for Research and Technology-

Hellas, Heraklion Crete, 71110, Greece

${ }^{5}$ School of Science and Technology, Nottingham Trent University, Nottingham, NG11

8NS, United Kingdom

*Corresponding author: ppats@physics.auth.gr

\section{KEYWORDS}

Refractory conductors; Plasmonics; Bottom-Up Fabrication; Defects; Second Harmonic Generation 


\begin{abstract}
TiN and $\mathrm{ZrN}$ are emerging as important alternative plasmonic materials. In addition to their well-known assets, they can incorporate point defects that break the centrosymmetry of their cubic crystal structure, making them promising candidates as non-linear optical materials and especially for second harmonic generation (SHG). Their refractory character and chemical stability were obstacles for the bottom-up fabrication of TiN and $\mathrm{ZrN}$ nanostructures so far. In this work, it is shown that highly directional dichroic nanostructures of TiN and $\mathrm{ZrN}$ may be indeed grown by self-assembly using glancing angle deposition on periodic rippled dielectric surfaces. The produced nitride nanostructures exhibit point defects and exceptional photothermal durability. These nanostructures exhibit strong SHG response when probed by a near-infrared laser. It is shown that SHG is strongly associated with the near-field enhancement due to the localized surface plasmon resonance of the nanostructures. Given that such nanostructures can endure extremely high electric fields, they are expected to be able to emit massive SHG signals and be applied in laser technology as optical components such as polarizers and SHG emitters.
\end{abstract}

\title{
I. INTRODUCTION
}

Transition metal nitrides (TMNs), predominantly TiN and $\mathrm{ZrN}$, are well-known optical conductors. Concomitantly, surface plasmon polaritons at TiN surfaces and localized surface plasmon resonance (LSPR) at TiN nanoparticles were observed as early as 2004 by Patsalas et al. [1] and Reinholdt et al. [2], respectively. In 2011, TMNs were proposed for the first time as realistic alternative materials for plasmonic devices by Naik 
et al. [3] due to the extraordinary combination of their properties that include refractory character [4], chemical and mechanical stability [5-8], and durability to high electric fields [9]; the latter also opens substantial opportunities for non-linear optics [9-11]. Since then, the relevant scientific interest, as attested by the number of published papers, shows a geometrical growth with an annual increase over $60 \%$. However, most of these works do not report the realization of TMN nanostructures in microelectronic architectures, instead they are dealing with continuous TMN layers (e.g. Ref. 12-16), computational works (e.g. Ref. 17-21), works evaluating the plasmonic potential of certain continuous films via their dielectric permittivity (e.g. Ref. 4, 20-24) and implementing specific figures of merit [25, 26], or colloidal nanoparticles [27-29] and powders [30,31]. This is mostly due to the difficulty of the bottom-up fabrication of nitride nanostructures due to their refractory character and to the covalent metal-nitrogen bonding [32] that prevent the melting and resolidification in realistic temperatures, as well as the differing optical properties of ultrathin TiN films compared to their opaque counterparts $[1,33]$. As a result, only a few experimental works can be found reporting the top-down fabrication of plasmonic devices [34-41]. In particular, the patterning methods employed so far for the fabrication of $\mathrm{TiN}$ and $\mathrm{ZrN}$ nanostructures include direct focused ion beam patterning [34], the combination of electron beam lithography [35-38] or nanoimprint lithography $[39,40]$ with reactive ion etching, and laser interferometry patterning with wet chemical etching $[9,41]$.

The quality of TMN films can vary significantly depending on the particular choice of one of the many available growth techniques. There is, unfortunately, a feature that is present in all manufacturing schemes: TMNs typically contain a considerable 
amount of point defects that are known to affect the properties of the host crystal $[42,43]$. Such difficulty in producing defect-free, ultra-thin TMNs, due to their refractory character, may turn from a curse into a blessing in the field of non-linear optics. The included point defects break locally the centrosymmety of the cubic structure, as attested by the Raman spectra of TMNs [44, 45]; the symmetry breaking is an essential prerequisite for the manifestation of second harmonic generation (SHG) [46, 47].

In this work, a large-scale, bottom-up, maskless, and etchless fabrication process of strongly dichroic and plasmonic $\mathrm{TiN}$ and $\mathrm{ZrN}$ nanostructures is presented. It is based on glancing angle deposition (GLAD) $[48,49]$ and reactive magnetron sputtering on prepatterned substrates [50]. The produced TiN and $\mathrm{ZrN}$ nanostructures have the form of aligned nanowires (NWs) with a more-or-less granular morphology, and they exhibit strong dichroism in the visible and near-infrared (NIR) ranges, as well as exceptional photothermal durability. The coherency of the nanostructures may be compromised in the case of multi-stack deposition that results in strong scattering of light. Thus, strong SHG may be present in such systems. Its occurrence is closely coupled with the plasmon resonance while its directionality is associated with the coherence of the nanostructures.

\section{RESULTS AND DISCUSSION}

\section{a. Fabrication Concept and Morphology of Nanostructures}

The steps of the reported self-assembly process are summarized in Fig. 1a. The selection of substrate is not critical as long as it is atomically flat. In this work, two 
substrates were implemented: fused silica for optical transmission measurements and SHG experiments, and conductive $n$-type $\mathrm{Si}(100)$ wafers (covered with a 2 -nm thick native oxide layer) for Raman spectroscopy experiments, as well as for morphology characterizations via Atomic Force Microscopy (AFM) measurements.

Amorphous alumina layers, $170 \mathrm{~nm}$ thick, were deposited on top of the various substrates by dual ion beam sputtering (DIBS) as described in more detail in Ref. 50. The second step of the process is the patterning of the amorphous alumina thin film by $1 \mathrm{keV}$ $\mathrm{Xe}^{+}$ion bombardment at oblique incidence $\left(55^{\circ}\right)$ to form periodic nanoripples [50]. The third step is the GLAD of TiN and $\mathrm{ZrN}$ on the rippled alumina surface via reactive magnetron sputtering. This step is particularly challenging for $\mathrm{TiN}$ and $\mathrm{ZrN}$ due to the combination of the reactive process associated with GLAD geometry, the high melting points of $\mathrm{TiN}$ and $\mathrm{ZrN}$ [21], the cohesive energies of $\mathrm{Ti}$ and $\mathrm{Zr}$ [51], the low work function [52], and the ionization potential [53] of $\mathrm{TiN}$ and $\mathrm{ZrN}$ compared to $\mathrm{Ag}$ and $\mathrm{Au}$. As a result, the $\mathrm{TiN}$ and $\mathrm{ZrN}$ reactive sputtering growth lies into the Zone 1 of limited diffusion and of high density of structural defects, according to the updated structural zone model of Anders [54], in contrast to Au and Ag that lie in Zone 3 of high crystallinity due to diffusion of adatoms [54]. In order to overcome these obstacles, the GLAD deposition ( $5^{\circ}$ angle of incidence) of $\mathrm{TiN}$ and $\mathrm{ZrN}$ was performed by reactive magnetron sputtering in the metallic cathode mode (i.e. strictly preventing poisoning of the target). The reactive gas $\left(\mathrm{N}_{2}\right)$ flow was delivered exclusively close to the substrate by a dedicated gas line monitored by a real-time mass spectrometer, and the ion bombardment conditions were kept mild and below the subplantation threshold [55] by applying a bias of $-60 \mathrm{~V}$ to the substrate during growth. The substrate temperature was 
tuned to $500{ }^{\circ} \mathrm{C}$, in order to maximize the surface diffusion of the deposited adatoms [ 54 , 55], while preventing the oxidation of the deposited nanostructures via diffusion of oxygen from the underlying alumina into the nitride (a process that might occur at $600{ }^{\circ} \mathrm{C}$ [7]). The deposition conditions used for this step are summarized in Table 1. The geometry of this step enables the growth of self-assembled and well-aligned nanostructures along the ripples, as we will show below, all over a macroscopic area, which is comparable to USD and Euro coins (shown in Fig. 1b).

Then, a selection of samples proceeded to step 4 , which is the in situ capping by an ultra-thin $(5 \mathrm{~nm})$ amorphous $\mathrm{SiN}_{\mathrm{x}}$ layer, grown by $\mathrm{RF}$ magnetron sputtering from a $\mathrm{Si}_{3} \mathrm{~N}_{4}$ ceramic target, in order to prevent oxidation and provide long-term stability to the nanostructures [30]. $\mathrm{SiN}_{\mathrm{x}}$ was selected due to its dielectric character as well as the thermal stability of the conductive nitride/ $/ \mathrm{Si}_{3} \mathrm{~N}_{4}$ nanostructures [56]. For selected samples, steps 3 and 4 were repeated in situ to form multi-stacks of TiN or $\mathrm{ZrN}$ nanostructures to enhance their far-field plasmonic features.

The formation of periodic ripple patterns on amorphous alumina surfaces subjected to $1 \mathrm{keV}-\mathrm{Xe}^{+}$ion bombardment at oblique incidence is well-documented and robustly reproducible [48-50]. The process results in near-parallel and slightly wavy ripples perpendicular to the ion-beam projection, as shown in the AFM images in the upper side of Fig. 2, all over the area of a macroscopic sample as shown in Fig. 1b. The AFM images can be quantified by considering the height variations along line scans in directions parallel or perpendicular to the ripples, as shown in Fig. S1 of on-line supplemental information. The height variations along the bare ripples are negligible, while the height variations across the ripples indicate a period $\Lambda$ of $26.0 \pm 1.1 \mathrm{~nm}$, and an 
average peak-to-valley height of $2.6 \pm 0.2 \mathrm{~nm}$ (note that the reported height and period values might be slightly affected by the radius of curvature of the tip, which is $\sim 10 \mathrm{~nm}$ ).

After the GLAD of TiN at $500{ }^{\circ} \mathrm{C}$ (Fig. 2, intermediate panels, and Fig. S1, green lines), the ripples retain their morphology and only some faint grainy structures appear at the highest resolution, which indicate the formation of continuous, yet rough, TiN NWs along the ripples. The difference of the determined period of the ripples after TiN deposition $(\Lambda=28.6 \pm 1.5 \mathrm{~nm})$ from the bare ripples is within the experimental error, while the peak-to-valley height across the ripples increases after TiN deposition to $3.3 \pm 0.4 \mathrm{~nm}$. Along the ripples, the root mean square roughness increases after TiN deposition, but no individual TiN nanoparticles can be identified.

The GLAD of ZrN results in a quite different morphology (Fig. 2, lower panels, and Fig. S1, magenta/purple lines). Again, the period of the nanostructures across the ripples $(\Lambda=29.6 \pm 2.2 \mathrm{~nm})$ is not substantially different from that of the bare ripples. However, the average peak-to-valley height becomes $4.5 \pm 0.7 \mathrm{~nm}$, indicating significant growth of $\mathrm{ZrN}$ on the alumina ripples. More striking differences are observed along the ripples after $\mathrm{ZrN}$ deposition. Indeed, clear features, characteristic of granular $\mathrm{ZrN}$ nanostructures, are identified along the ripples; their period and average peak-to-valley height are $19.1 \pm 3.4 \mathrm{~nm}$ and $1.5 \pm 0.1 \mathrm{~nm}$, respectively. Based on the observed morphologies and the quantitative data, it can be safely concluded that $\mathrm{ZrN}$ after GLAD forms highly oriented arrays of densely-packed nanoparticles resulting in granular-like NWs along the underlying ripples. The difference in the morphology of the produced TiN and $\mathrm{ZrN}$ nanostructures, i.e. quite smooth NWs vs arrays of granular NWs, respectively, 
may be assigned to a variety of reasons, such as differences in angular and energy distribution of sputtered atoms reaching the substrate at glancing angle, and the reduced mobility of $\mathrm{Zr}$ adatoms on the active growing surface $[57,58]$. The reported morphological features do not change after the deposition of the homogeneous $5 \mathrm{~nm}$ ultrathin $\mathrm{SiN}_{\mathrm{x}}$ capping layer over the $\mathrm{TiN}$ or $\mathrm{ZrN}$ nanostructures (Fig. 1a, step 4). When the GLAD of TiN or $\mathrm{ZrN}$ and the sputter deposition of the homogenous $\mathrm{SiN}_{\mathrm{x}}$ capping layer are repeated three times, in order to produce triple arrays of nanostructures and increase their linear as well as non-linear plasmonic response, the surface morphology of the top array of nanostructures is less organized and coherent as it is shown in the on-line supplemental information (Fig. S2). A possible explanation for this difference in morphology is most likely due to the roughness and morphology of the underlying layers of nanostructures that alter the shadowing and surface diffusion conditions during GLAD. Such loss of coherency sets the limit of repetitions in this process and defines the maximum interaction volume with the incident light; it also affects the linear and nonlinear optical properties of the TMN nanostructures, as it will be discussed later.

It is worth noting that the proposed process is generic and might be very efficient for the production of nanostructures of a wide variety of alternative non-metallic conductors, which are usually grown by sputter deposition, such as molybdenum nitride (MoN) [59], tantalum nitride (TaN) [20, 22 60], niobium nitride ( $\mathrm{NbN}$ ) [61], In-doped tin oxide (ITO) [22, 62, 63], aluminum- or gallium-doped zinc oxide (AZO, GZO) [22, 62, 64, 65], niobium-doped titanium oxide (NTO) [66], partly reduced molybdenum oxides $\mathrm{MoO}_{\mathrm{x}}(\mathrm{x}<3)[67,68]$, and vanadium dioxide $\left(\mathrm{VO}_{2}\right)$, which exhibits a metal-insulator transition $[69,70]$. All these conductors have been proposed as alternative plasmonic 
materials, whose plasmonic activity spans the far ultraviolet to medium infrared range [1, $20,22,59,61,71-79]$.

\section{b. Vibrational Properties and Photothermal Stability}

In addition to the morphological features, it is important to clarify whether the formed TMN nanostructures adopt the B1 rocksalt crystal structure, which is the phase that exhibits strong plasmonic performance [21, 45], or not. The Raman spectra of $\mathrm{ZrN}$ and TiN are characterized by distinct features [44, 45, 80-84], which are associated with the first order transverse acoustic (TA) and longitudinal acoustic (LA) modes. These peaks are normally forbidden because of the $O_{h}$ symmetry of the rocksalt structure, and they emerge only in the presence of defects that break the local symmetry. Therefore, the usefulness of the Raman spectra is twofold; it serves the non-destructive identification of the $\mathrm{B} 1$ rocksalt phases of $\mathrm{ZrN}$ and $\mathrm{TiN}$, as well as the detection of point defects that break the symmetry of the cubic, centrosymmetric $\mathrm{ZrN}$ and $\mathrm{TiN}$.

Figure 3 shows the polarized Raman spectra of the $\mathrm{ZrN}$ and $\mathrm{TiN}$ nanostructures (both single- and triple-arrays) with the electric field of the probe laser beam being linearly polarized across (denoted $\perp$ for perpendicular) or along (denoted $\|$ for parallel) the ripples. For the Raman experiments, silicon replaced silica as the substrate for the process presented in Fig. 1, in order to eliminate the broad Raman signal from silica [73] that overlaps with the spectra of $\mathrm{TiN}$ and $\mathrm{ZrN}$. The corresponding Raman spectra from opaque epitaxial films from Ref. 81 are also shown for comparison. All the spectra exhibit a doublet at low frequencies (below $350 \mathrm{~cm}^{-1}$ ), which is assigned to the first order TA and LA modes. As mentioned previously, this doublet is exclusively due to the 
presence of point defects that break the $O_{h}$ symmetry of the rocksalt (B1) structure. The Raman features at higher frequencies originate from the overlapping of the first order optical (O) and the second order acoustic modes (2A), according to Spengler et al. [44]. The comparison of the Raman spectra of the nanostructures with those of the epitaxial films firmly identifies the B1 rocksalt crystal structure. This was further confirmed by Xray and electron diffraction studies (not reported here). The epitaxial films exhibit sharper features than the reported nanostructures due to the improved crystallinity. It is important to note that for all samples, there is no significant change of the broadening of the Raman features between the spectra of the two beam polarizations (along and across the ripples), indicating that there is no preferable axis of improved crystallinity despite of the linear ordering of the nanostructures along the ripples.

Spengler et al. also associated the intensity ratio of the first order acoustic modes and the broad envelope of $\mathrm{O}$ and $2 \mathrm{~A}$ modes with the density of point defects that break locally the $O_{h}$ symmetry. Indeed, it has been very recently demonstrated that this ratio is well-scaled with the formation energy of vacancies in all the conductive TMNs [81]. The frequencies $\omega_{\mathrm{TA}}, \omega_{\mathrm{LA}}, \omega_{\mathrm{O}} \& 2 \mathrm{~A}$ of the TA, LA modes and of the O\&2A envelope, respectively, as well as the intensity ratio $\mathrm{I}_{\mathrm{TA}} / \mathrm{I}_{\mathrm{O} \& 2 \mathrm{~A}}$ of the TA peak over the O\&2A envelope are summarized in Tables S1 and S2 of the on-line supplemental information for $\mathrm{ZrN}$ and $\mathrm{TiN}$, respectively. Several aspects have been revealed from the quantitative results. Firstly, the frequencies of the TA and LA modes and the O\&2A envelope of the epitaxial films are in remarkable agreement with previous studies on stoichiometric nitrides $[44,82,83]$. Secondly, the TA and LA modes of both TiN and $\mathrm{ZrN}$ nanostructures are shifted compared to the corresponding epitaxial films; this is more 
pronounced for the TA mode that exhibits shifts higher than $17 \mathrm{~cm}^{-1}$ and $5 \mathrm{~cm}^{-1}$ for TiN and $\mathrm{ZrN}$, respectively. Such shifts were assigned to deviations from stoichiometry both for $\mathrm{TiN}[44,83]$ and $\mathrm{ZrN}$ [84]. Therefore, the produced TMN nanostructures may not be stoichiometric. Importantly, for the SHG applications, the $\mathrm{I}_{\mathrm{TA}} / \mathrm{I}_{\mathrm{O} \& 2 \mathrm{~A}}$ ratio is increased by $66 \%$ and $18 \%$ in $\mathrm{TiN}$ and $\mathrm{ZrN}$ nanostructures, respectively, compared to the epitaxial samples. This ratio was associated with the point defects [81] and the results show that the TiN nanostructures incorporate more defects than the $\mathrm{ZrN}$ nanostructures. Indeed, it was shown that at the very initial stages of growth, for thickness less than $6 \mathrm{~nm}$, TiN is not stoichiometric and exhibits a high concentration of defects [1]. Last but not least, this ratio does not vary significantly along and across the ripples indicating that there is no preferred directionality for the accumulation of defects.

The Raman experiments may also be used to test the photothermal stability of the produced nanostructures. To check and demonstrate the photothermal stability, especially across the ripples where the size of the nanostructures is just few nanometers, Raman spectra were acquired from the single-array $\mathrm{ZrN}$ nanostructures with polarization across the ripples, varying the power of the probe laser beam. The relevant spectra for 1,5 , and $20 \mathrm{~mW}$ continuous wave laser probe are shown in the upper panel of Fig. 3 with different shades of grey; all the spectra are identical with no traces of bulk oxidation or formation of additional defects in the $\mathrm{ZrN}$ nanostructures. Given that the spot size of the probe laser beam is $\sim 1 \mu \mathrm{m}$ on sample, the maximum power density used is $2.5 \mathrm{MW} / \mathrm{cm}^{2}$, which is one order of magnitude higher than the power density used for the sintering of colloidal Ag inks [85] and comparable with the pulsed laser power used for the melting of Ag layers [86] and the diffusion of melted Ag out of yttria scaffolds [87]. Therefore, the $\mathrm{ZrN}$ 
nanostructures exhibit remarkable and extraordinary photothermal stability that easily outperforms plasmonic Ag nanostructures.

\section{c. $\quad$ Linear and Non-Linear Optical Properties}

The far-field optical properties of the formed TMN nanostructures are characterized by strong dichroism and plasmonic effects. This is clearly demonstrated in the polarized optical absorbance spectra of Fig. 4 (calculated from raw optical transmission spectra). The left and center panels show the optical absorbance spectra for two bare and two $\mathrm{SiN}_{\mathrm{x}}$-capped $\mathrm{TiN}$ and $\mathrm{ZrN}$ arrays of nanostructures, respectively, with electric field across ( $\perp$, solid lines) and along ( $\|$, dotted lines) the ripples. For both cases, the dichroism is not prominent for short wavelengths (shorter than $400 \mathrm{~nm}$ or $3.1 \mathrm{eV}$ and $350 \mathrm{~nm}$ or $3.5 \mathrm{eV}$ for $\mathrm{TiN}$ and $\mathrm{ZrN}$, respectively); the increased absorbance in this range is due to the interband transitions of $\mathrm{TiN}$ and $\mathrm{ZrN}$ and it is consistent with the interband absorption reported for continuous opaque TiN and $\mathrm{ZrN}$ films [1, 20, 21, 45].

In the case of the bare TiN nanostructures, there is a strong dichroism mostly in the NIR range, with a prominent localized absorbance peak centered around $1200 \mathrm{~nm}$ $(1.03 \mathrm{eV})$ for the electric field in the perpendicular direction, i.e. across the ripples and nanostructures. This peak is assigned to LSPR due to the infinitesimal size of the TiN nanostructures across the alumina ripples. The plasmonic hypothesis is confirmed by the comparison of the optical absorbance spectra of bare (Fig. 4, red solid line) and $\mathrm{SiN}_{\mathrm{x}^{-}}$ capped nanostructures (Fig. 4, orange solid line). The absorbance peak of the $\mathrm{SiN}_{\mathrm{x}}-$ capped nanostructures is substantially redshifted to $1860 \mathrm{~nm}(0.67 \mathrm{eV})$ due to the higher refractive index of the surrounding $\operatorname{SiN}_{x}(n \sim 2)$ compared to air $(n \sim 1)$, as indicated by the 
black arrows. This proves unequivocally the plasmonic nature of this optical feature. The LSPR of the bare TiN nanostructures lies into the NIR range and not in the visible as it would be anticipated for spherical nanoparticles [21]. This can be explained by the high concentration of defects, as indicated by the Raman spectra, as well as the flatness of the TiN NWs and the short edge-to-edge distance between NWs. LSPR can be also substantially redshifted and weakened in ultrathin TiN due to stoichiometry variations [88] and the incorporation of surface oxygen species [89], which are both depleting the conduction electrons. In addition, it was previously shown that for ultra-thin TiN deposits $(<6 \mathrm{~nm})$ the nitride is inherently defective even if the deposition conditions are appropriate for the growth of stoichiometric TiN at higher thicknesses [1]. In the parallel direction of the electric field (along the ripples and nanostructures), no such peaks are observed in the experimental spectral window, and therefore the optical response of TiN nanostructures is more consistent with an infinite $1 \mathrm{D}$ conductor.

The case of the $\mathrm{ZrN}$ nanostructures is more complex and interesting. The dichroism and the plasmonic features are manifested not only in the NIR, but also extend into the visible range (Fig. 4, center panel). In the perpendicular direction of the electric field (across the ripples), the LSPR of bare $\mathrm{ZrN}$ nanostructures is vaguely manifested through a shoulder around $500 \mathrm{~nm}(2.48 \mathrm{eV})$ (Fig. 4, blue solid line), a value consistent with what would be expected for $\mathrm{ZrN}$ spherical nanoparticles [21, 45]. This LSPR is redshifted, like in the case of $\mathrm{TiN}$, to $580 \mathrm{~nm}(2.14 \mathrm{eV})$ for the $\mathrm{SiN}_{\mathrm{x}}$-capped $\mathrm{ZrN}$ nanostructures (Fig. 4, cyan solid line). However, as opposed to the case of TiN NWs, for the parallel field (along the ripples) both bare and $\mathrm{SiN}_{\mathrm{x}}$-capped $\mathrm{ZrN}$ nanostructures exhibit another plasmonic absorption band in the NIR around 1130 and $1200 \mathrm{~nm}$ (1.10- 
$1.03 \mathrm{eV}$ ), respectively. In contrast to TiN, where dichroism originates from the existence or not of a plasmonic absorption band, in $\mathrm{ZrN}$ nanostructures the dichroism is due to the existence of two distinct plasmonic features at the two polarizations of the incident light. While the LSPR in the visible range and for the perpendicular field is very well understood and resembles the optical response of the TiN nanostructures, the nature of the plasmonic feature in the NIR for the parallel field may originate from the granular structure of the $\mathrm{ZrN}$ nanostructures. Indeed, the particle-particle near field interaction of the $\mathrm{ZrN}$ dense granular nanostructure may result in the observed substantial redshift [9092]. Finally, the $\mathrm{ZrN}$ and TiN multi-stacks retain the plasmonic features of their capped single-array counterparts, albeit with stronger far-field optical absorption due to the cumulative interactions of each array of nanostructures with the incoming light (Fig. 4, right panel).

In order to shed some light on the plasmonic performance of the $\mathrm{ZrN}$ and $\mathrm{TiN}$ nanostructures interacting with the perpendicular electric field $(\perp)$, Finite-Difference Time-Domain (FDTD) calculations were carried out. An in-house 3D FDTD simulator $[93,94]$ was used in all calculations. Arrays of one-dimensional rods with infinite length and semi-elliptic cross section at a constant center-to-center distance of $\Lambda=30 \mathrm{~nm}$ (roughly the period of ripples on the substrate) were considered for the calculations, as shown in Fig. 5a. The calculations were carried out for a range of aspect ratios $H / D$ (where $H$ and $D$ are the height and diameter of the rods, respectively) in adequacy with the AFM experimental observations and with the aim of reproducing the experimental position of the absorbance maxima. We used dielectric functions retrieved from ellipsometric measurements of continuous opaque $\mathrm{ZrN}$ and $\mathrm{TiN}$ films deposited at near- 
normal incidence in the same conditions as the TMN nanostructures. The incoming electric field was set perpendicular $(\perp)$ to the infinite axes of the rods. The far-field optical absorbance (see on-line supplemental information, Fig. S3), as well as the distributions of the electric near-field enhancement (NFE) for the excitation wavelength $(1030 \mathrm{~nm})$ of the laser used for the SHG experiments, were calculated. The FDTD results unequivocally show that the far-field properties (Fig. S3) are substantially affected by the morphology of the nanostructures, as it is shown in the contour plots of the wavelength of the absorbance maximum for varying $\mathrm{D}$ and $\mathrm{H}$ values for $\mathrm{ZrN}$ (Fig. 5b) and TiN (Fig. 5c). In Fig. 5c (upper panel), the thick green line corresponds to the experimental position of the LSPR maximum for the bare TiN nanostructures (i.e., $1200 \mathrm{~nm}$ ). Our calculations confirm that the LSPR redshift compared to the expected position for spherical TiN nanoparticles in air (520 nm [1]) originates from flat and coupled TiN NWs. Several $(H, D)$ couples lead to consistency between the experimental and calculated spectral positions of LSPR maximum. Nevertheless, considering the nominal equivalent thickness of $\mathrm{TiN}(3.7 \mathrm{~nm}$, Table 1$)$, the best $(H, D)$ couple that could explain the experimental position is $D=28 \mathrm{~nm}$ and $H=2.4 \mathrm{~nm}$, corresponding to very flat $(H / D<$ $0.1)$ and highly coupled $(x=\Lambda-D=2 \mathrm{~nm}<D / 10)$ TiN nanostructures. The existence of nanogaps between plasmonic nanostructures associated with LSPR coupling were reported to result in strong redshift of the far-field absorbance and reflectance as well as exceptional NFE at the formed hot spots [95]. As shown in Fig. 5c (lower panel), the corresponding calculated positions of the LSPR for $\mathrm{SiN}_{\mathrm{x}}$-capped TiN nanostructures are even more redshifted in the NIR in agreement with the experimental observations. In the case of $\mathrm{ZrN}$ nanostructures, considering a nominal equivalent thickness of $7.6 \mathrm{~nm}$ (Table 
1), the best $(H, D)$ couple that explains the experimental position of LSPR maximum for the $\mathrm{SiN}_{\mathrm{x}}$-capped sample, which is clearly identified at $580 \mathrm{~nm}$ in Fig. 4, center panel (see thick green line in the contour plot of Fig. 5b, lower panel), is $H=17 \mathrm{~nm}$ and $D=18 \mathrm{~nm}$. Therefore, for the $\mathrm{ZrN}$ nanostructures, the out-of-plane aspect ratio $H / D$ is close to 1 (0.9) with an edge-to-edge distance $x=12 \mathrm{~nm}$ (higher than $D / 2$ ). The corresponding calculated position of the LSPR maximum for the bare $\mathrm{ZrN}$ nanostructures is obtained at $515 \mathrm{~nm}$ (Fig. 5b, upper panel) in line with the experimental shoulder around $500 \mathrm{~nm}$ (Fig. 4, center panel). In that case, FDTD calculations show that the deviation from what is expected for spherical nanoparticles in air in terms of LSPR spectral position is less prominent. The distributions of NFE at $1030 \mathrm{~nm}$ (the excitation wavelength which was used for the SHG experiments) for simulated bare nanostructures with appropriate $(H, D)$ values are shown in Fig. 6a,b. In both cases, the maximum NFE is located at the bases and edges of the nanostructures. The NFE in the case of 'isolated' $\mathrm{ZrN}$ nanostructures is moderate $(\sim 30)$ and it is remarkably enhanced for the case of the coupled TiN nanostructures $(\sim 100)$ due to the formation of hot spots.

By comparing the Raman with the optical absorbance spectra, we reveal an extraordinary feature of conductive albeit defective nitride nanostructures: TMNs exhibit a unique combination of broken centrosymmetry (due to defects and refractory character) and plasmonic activity with great potential for SHG. This is in contrast to the traditional plasmonic metals $(\mathrm{Au}, \mathrm{Ag}$ ), which exhibit zero second-order susceptibility due to their centrosymmetric $f c c$ crystal structure [96-98]. Continuous stoichiometric TiN films exhibit very weak SHG [99], possibly due to the low concentration of defects in such TiN structures. Although the crystal symmetry may be broken at metallic surfaces [96], for 
centrosymmetric nanostructures (as those presented in this work) the contribution of two opposing surface elements cancels out in the far-field in the dipole approximation [97, 98]. Consequently, plasmonic nanostructures consisting of $\mathrm{Au}$ or $\mathrm{Ag}$ that are capable of SHG are based on metamaterials with non-centrosymmetric shapes [98, 100-102]. In the same context, TiN was implemented as a conventional metal component of noncentrosymmetric metamaterials, such as split-ring resonators [103] and chiral core-shells [104] for SHG, regardless of its own intrinsic broken centrosymmetry. So far, there is no report on optical non-linearities of $\mathrm{ZrN}$ whatsoever.

Figure 7 shows the polar diagrams of polarized SHG (PSHG) with a pump beam of $1030 \mathrm{~nm}(1.204 \mathrm{eV})$ using the same gain for all cases; in this diagram zero degree is for the electric field of the pump beam being aligned along the ripple direction. An exceptionally interesting observation is that the SHG is emitted along (\| field) the ripples for $\mathrm{ZrN}$ and across ( $\perp$ field) the ripples for TiN. This strikingly different behavior of the two sets of TMN nanostructures may be well explained if we consider their optical properties presented in Fig. 4. Indeed, ZrN exhibits a broad LSPR band around $1200 \mathrm{~nm}$ $(1.03 \mathrm{eV})$ when the electric field of the light is parallel to the ripples, possibly due to the granular structure of the $\mathrm{ZrN}$ nanostructures that promotes the particle-particle near field interaction. On the other hand, TiN exhibits a similar LSPR band around $1200 \mathrm{~nm}(1.03$ $\mathrm{eV}$ ) when the electric field is perpendicular to the ripples due to the infinitesimal size of the TiN nanostructures across the alumina ripples. In both cases the $1030 \mathrm{~nm}$ probe beam lies within the bandwidth of the LSPR, while it lies far beyond the strong LSPR of $\mathrm{ZrN}$ across the ripples $(<600 \mathrm{~nm})$. So, the TMN nanostructures act simultaneously as the probe (defects and broken centrosymmetry) and pump (LSPR field enhancement) 
medium for SHG. Note that this plasmon-pumped generation of second harmonic is contrastingly different to the work of Huang et al [105], where the SHG from the defective tantalum nitride (TaN) is pumped by the enhanced near field due to the LSPR in adjacent gold nanopillars, i.e. the pumping plasmon is not due to the nitride conductor itself.

The SHG is apparently stronger for $\mathrm{ZrN}$, although TiN seems more defective both in the Raman (Fig. 3) and absorbance (Fig. 4) spectra. This might be attributed to the stronger LSPR in NIR for ZrN nanostructures, as well as the better overlap of ZrN LSPR with the probe beam. For optimal plasmon-pumped SHG in such defective TMN nanostructures there is a sensitive interplay between two competing mechanisms; a lot of defects increase the density of sites of broken symmetry, potentially enhancing the SHG, but at the same time they deteriorate the LSPR and the near-field enhancement, which is necessary for the SHG. In addition, the granular nature of the $\mathrm{ZrN}$ nanostructures may promote the creation of a high linear density of hot spots with great NFE along the ripples; this is supported by the redshifted LSPR along the ripples.

It is also interesting to follow the variations of directionality of PSHG polar diagrams; this is better illustrated in the cartesian SHG diagram presented in the on-line supplemental information (Fig. S4). The bare nanostructures, both $\mathrm{ZrN}$ and $\mathrm{TiN}$, produce highly directional PSHG polar diagrams. This is well understood by considering that the non-linear dipoles, which define the directionality of SHG [106], are strictly directional due to the geometry of the pumping LSPR. The $\mathrm{SiN}_{\mathrm{x}}$-capping does not alter substantially the directionality. Finally, the multi-stacks clearly exhibit a partial loss of directionality, possibly due to the scattering of the SHG from the incoherent top arrays of nanostructures 
(see Fig. S2). Such variations of directionality along or across the ripples, or their reduction due to loss of coherence of the nanostructures, provide exceptional versatility for optical devices and applications.

\section{CONCLUSIONS}

An etchless, cost-effective and novel bottom-up fabrication route to produce nanostructures of the refractory and alternative plasmonic materials $\mathrm{TiN}$ and $\mathrm{ZrN}$ was presented. It is based on glancing angle deposition by reactive magnetron sputtering on prepatterned (nanorippled) alumina substrates. The process is generic and could be applied to a wide range of alternative plasmonic materials that are traditionally grown by reactive magnetron sputtering, such as the entirety of TMNs and transparent conductive oxides.

The produced nanostructures are nearly one dimensional, and they are strongly dichroic due to the different LSPR features along or across their axis. TiN and $\mathrm{ZrN}$ are refractory and so the produced nanostructures exhibit exceptional photothermal stability as demonstrated by Raman spectroscopy. Raman spectra also revealed the existence of a higher density of point defects than that of the corresponding continuous epitaxial films. Remarkably, these defects break the centrosymmetry of the cubic crystal structure of TiN

and $\mathrm{ZrN}$, while the plasmonic performance of the nitrides is retained. The combination of broken centrosymmetry with the plasmonic activity results in strong SHG. The directionality of the SHG depends on the type of plasmonic interaction (along the nanostructures for $\mathrm{ZrN}$ and across the nanostructures for $\mathrm{TiN}$ ) and the coherence of the 
individual linear nanostructures. Their traits of strong dichroism and SHG make them suitable for laser technology as optical components such as polarizers and SHG emitters.

\section{METHODS}

\section{Experiments:}

The surface morphology of the nanostructures was analyzed immediately after deposition by AFM using a multimode Digital Instrument microscope operating in tapping mode at ambient conditions.

Raman spectroscopy measurements were conducted with a Horiba LabRAM HR instrument with a $515 \mathrm{~nm}$ excitation laser; the excitation laser was selected such that its energy is spectrally located beyond the reflectivity edge of $\mathrm{TiN}$ and $\mathrm{ZrN}$ and, therefore, to minimize the skin effect. A linearly polarized excitation beam was used to identify potential variations of the Raman spectra with beam polarization parallel $(\|)$ or perpendicular $(\perp)$ to the $\mathrm{TiN}$ and $\mathrm{ZrN}$ nanostructures.

The far-field optical response of the self-assembled nanostructures was investigated by means of transmission spectroscopy using a Cary 5000 spectrophotometer from Agilent Technologies equipped with a rotating polarizer. Transmittance measurements were performed at normal incidence (beam diameter $\sim 3 \mathrm{~mm}$ ) in the spectral range $250-2200 \mathrm{~nm}(4.96-0.56 \mathrm{eV})$ with a $1 \mathrm{~nm}$ step using parallel $(\|)$ or perpendicular $(\perp)$ polarization with respect to the alumina ripple direction. 
Polarization-resolved SHG measurements were carried out using a custom-built laser scanning microscope as described in detail in Ref. 47, using the beam from a diodepumped Yb:KGW fs oscillator (1.2 W, 1030nm, 70-90 fs, $76 \mathrm{MHz}$, Pharos-SP, Light Conversion) and an inverted microscope (Axio Observer Z1, Carl Zeiss).

\section{Computational Method:}

The calculations of the optical response of the TiN and $\mathrm{ZrN}$ nanostructures were performed by time-integrating Maxwell's equations on a computational grid utilizing the Finite-Difference Time-Domain (FDTD) method, using an in-house built 3D simulator provided by E. Lidorikis [93, 94]; key features of the results were confirmed by FDTD calculations using Lumerical $^{\mathrm{TM}}$.

In the computational process, the material dispersion is introduced in the form of polarization equations coupled and solved concurrently with Maxwell's equations. To accurately reproduce the optical constants of B1-TiN and B1-ZrN, within the FDTD framework, we performed a Drude-Lorentz fit $[21,45]$ to the experimental dielectric functions of opaque stoichiometric $\mathrm{ZrN}$ and $\mathrm{TiN}$ films obtained in the same conditions and measured by spectroscopic ellipsometry. 
Table 1: Conditions of the GLAD growth of TiN and ZrN

\begin{tabular}{|c|c|c|}
\hline & TiN & ZrN \\
\hline DC Cathode Power (W) & 300 & 300 \\
\hline Angle of Incidence $\left(^{\circ}\right)$ & 5 & 5 \\
\hline $\mathrm{N}_{2}$ flow at the substrate (sccm) & 0.3 & 0.5 \\
\hline Ar flow at the cathode (sccm) & 12 & 15 \\
\hline Partial pressure of $\mathrm{N}_{2}\left(\right.$ mbar $\left.\times 10^{-5}\right)$ & $5-7$ & $5-7$ \\
\hline Working pressure $\left(\right.$ mbar $\left.\times 10^{-3}\right)$ & 2.3 & 2.6 \\
\hline Base Pressure $\left(\right.$ mbar $\left.\times 10^{-8}\right)$ & $<5$ & $<5$ \\
\hline Substrate Temperature $\left({ }^{\circ} \mathrm{C}\right)$ & 500 & 500 \\
\hline DC Negative Bias Voltage $(V)$ & 60 & 60 \\
\hline Deposition Time $(s)$ & 80 & $\begin{array}{l}120 \text { single } \\
80 \text { multi }^{*}\end{array}$ \\
\hline Nominal equivalent thickness (nm) & 3.7 & 7.6 \\
\hline
\end{tabular}

*The deposition time used for ZrN multistacks was shorter than that for single arrays of nanostructures in order to minimize the loss of organization of the upper layer due to the granular morphology of the underlayers. 


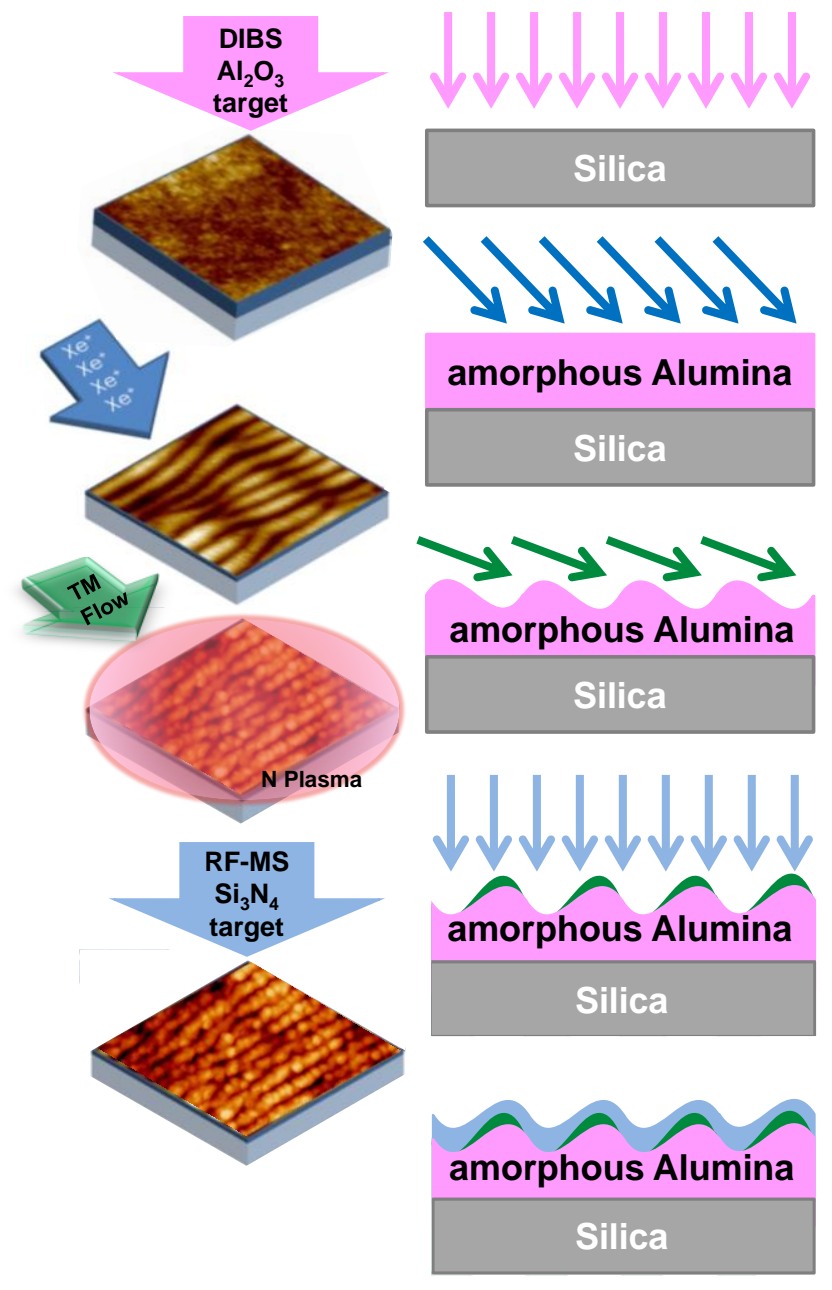

(a)

Step 1: Template

Formation

Deposition of Alumina on a

flat substrate

Step 2: Ripple Formation $1 \mathrm{keV} \mathrm{Xe}+$ ion bombardment at oblique incidence $\left(55^{\circ}\right)$

Step 3: Nanowire Deposition Reactive sputtering of TiN or $\mathrm{ZrN}$ at Glancing Angle (5०) Deposition (GLAD) conditions

\section{Step 4: Capping}

RF sputtering of $\mathrm{SiN}_{\mathrm{x}}$ at Near-normal Deposition conditions

(b)

Fig. 1: (a) Schematic of the process used for the bottom-up fabrication of dichroic and plasmonic TMN nanostructures; the left panels are based on AFM images of real samples at each step of the fabrication process. (b) The physical dimensions of the samples compared with a Euro coin and a quarter US dollar; coloration appears only under polarized light. 

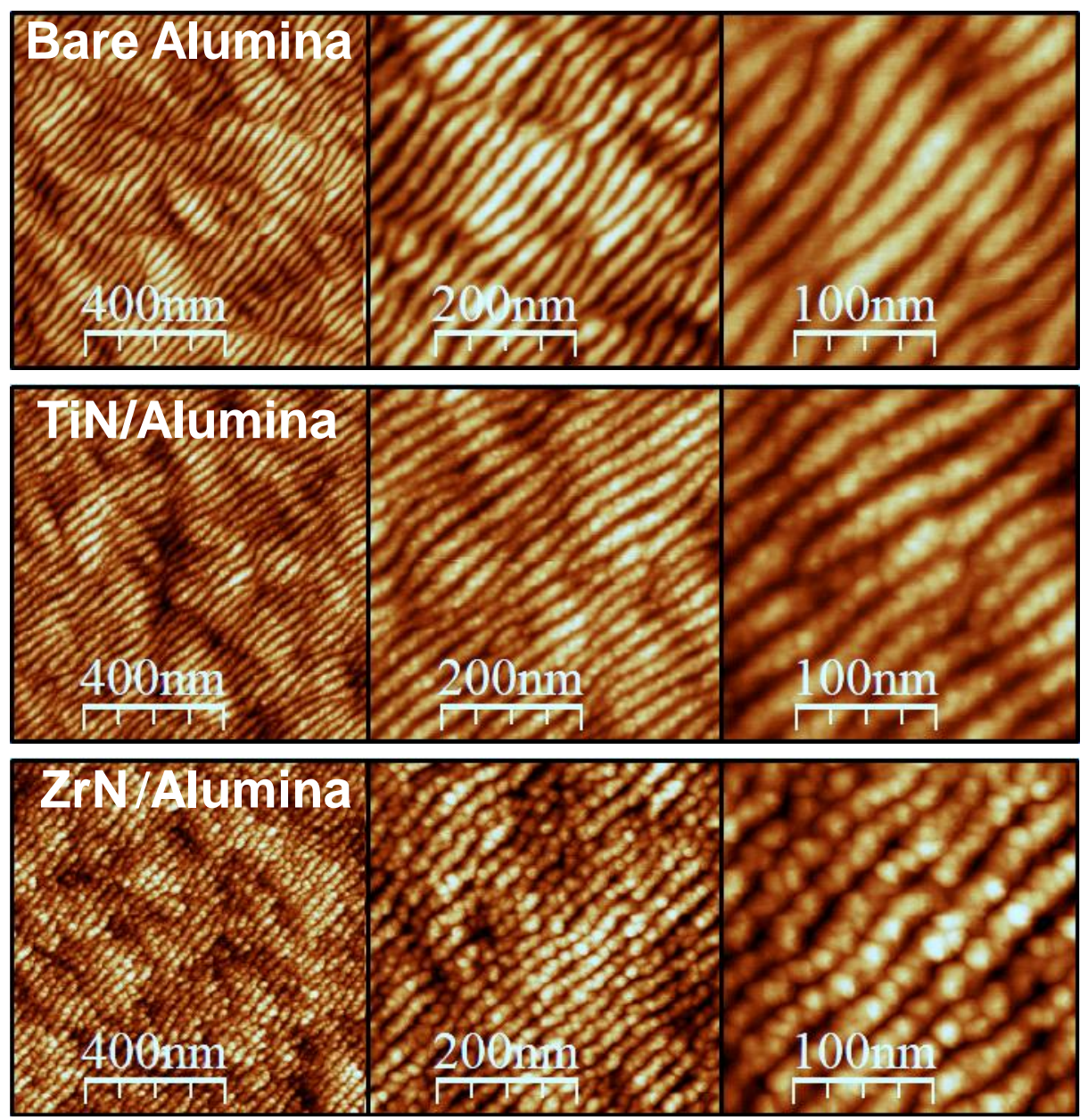

\section{$12 \mathrm{~nm}$}

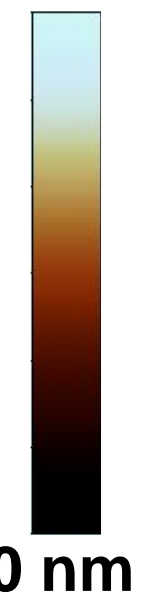

Fig. 2: Morphology of representative NWs of $\mathrm{ZrN}$ (lower panels) and $\mathrm{TiN}$ (intermediate panels) on rippled alumina substrates (upper panels) as observed by AFM. 


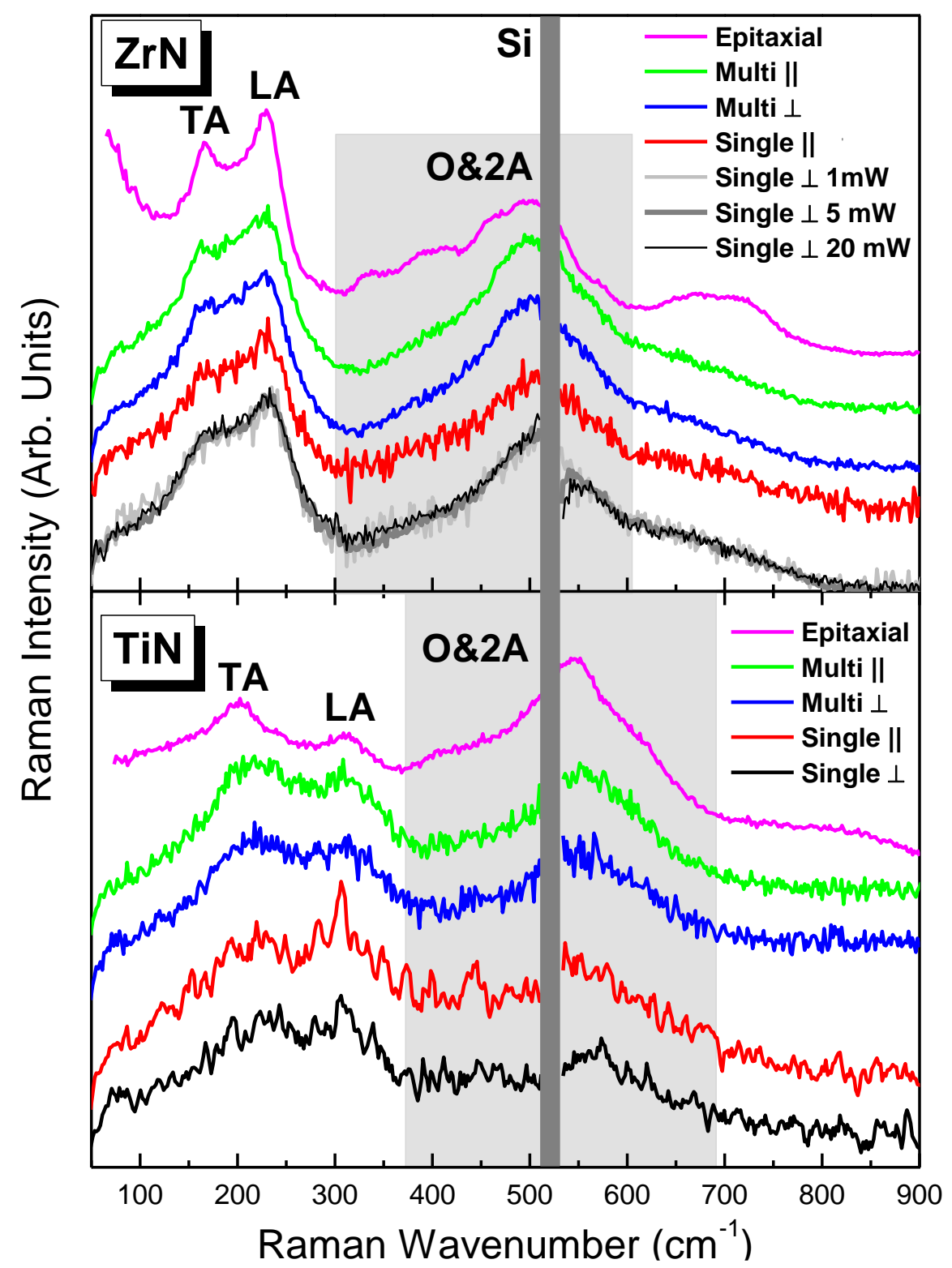

Fig. 3: Polarized Raman spectra of the single- and triple- (multi) arrays of $\mathrm{ZrN}$ and TiN nanostructures with the laser beam polarized along $(\|)$ and across $(\perp)$ the ripples; the spectra of the corresponding epitaxial opaque films from Ref. 81 are also shown for comparison. The light grey shaded area indicates the spectral range of the overlapping 2TA, 2LA and $\mathrm{O}$ modes (denoted as 2A\&O), while the dark grey shaded area indicates the spectral location of the very narrow and strong Raman peak of the Si substrate that is removed from the nitride spectra for clarity. 

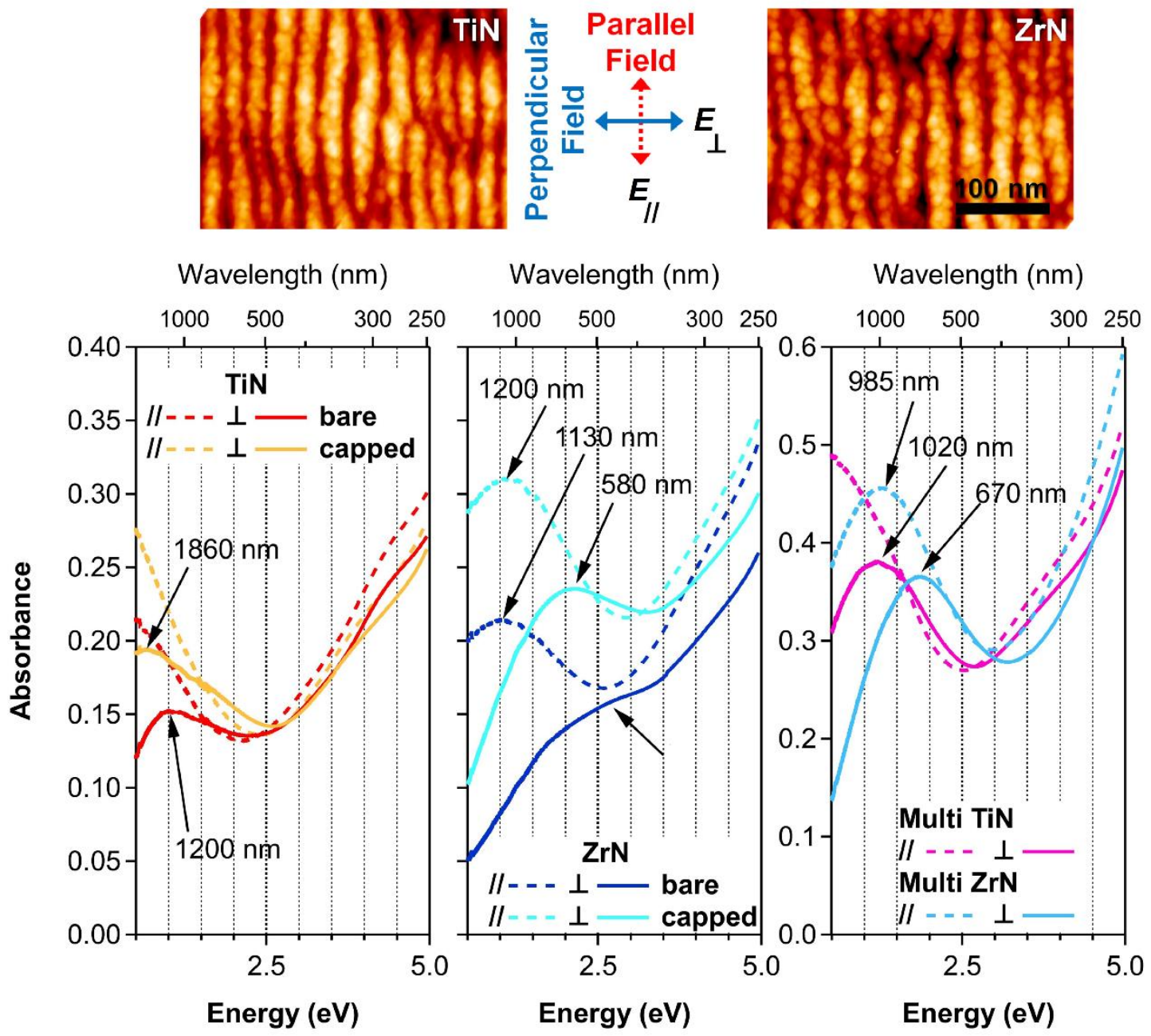

Fig. 4: Optical absorbance spectra of TiN (lower left panel) and $\mathrm{ZrN}$ (lower center panel) nanostructures, and multi-stacks (lower right panel), with or without $5 \mathrm{~nm} \mathrm{SiN}$ capping; solid and dotted lines represent data obtained for perpendicular $(\perp)$ and parallel $(\|)$ electric fields, respectively, with respect to the ripples, as defined in the upper panels of the figure. Arrows indicate the spectral positions of the LSPR maximum for each spectrum. 

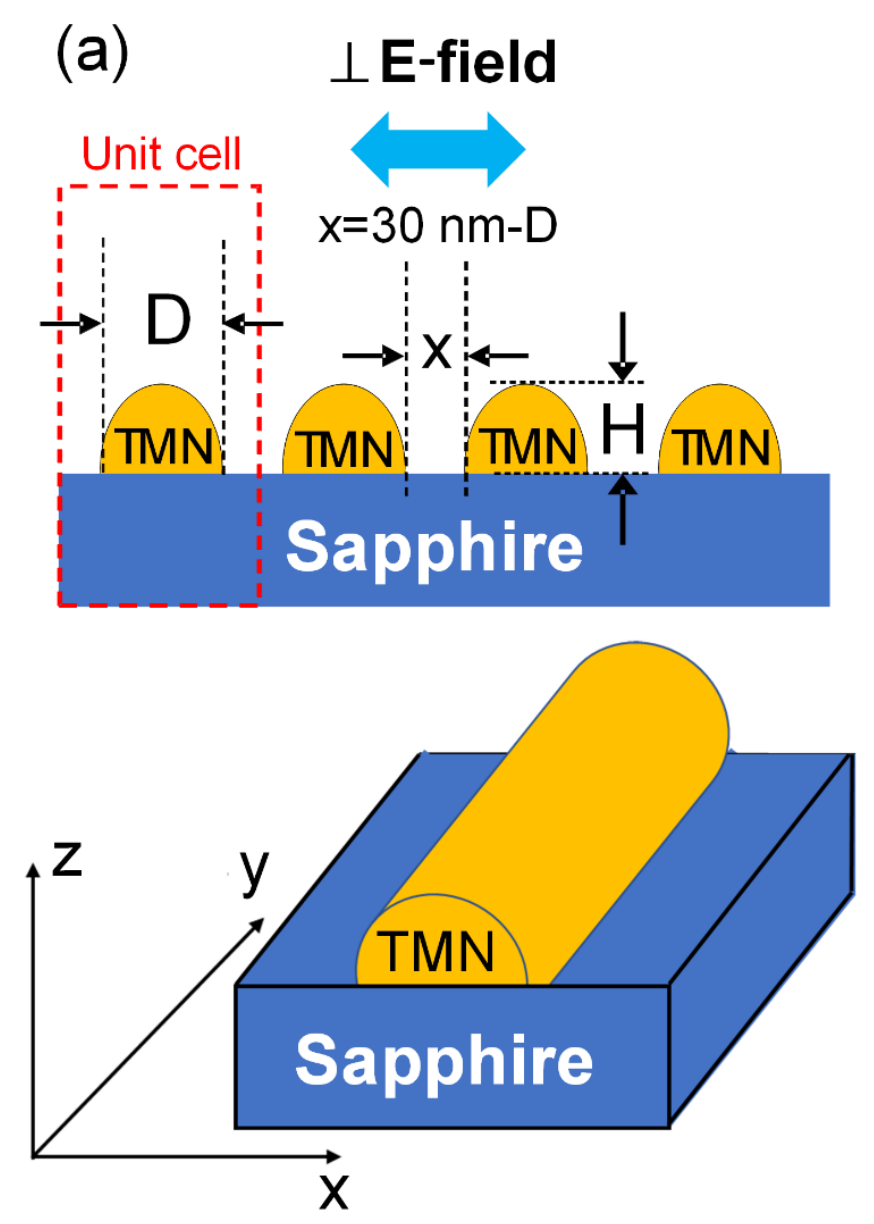

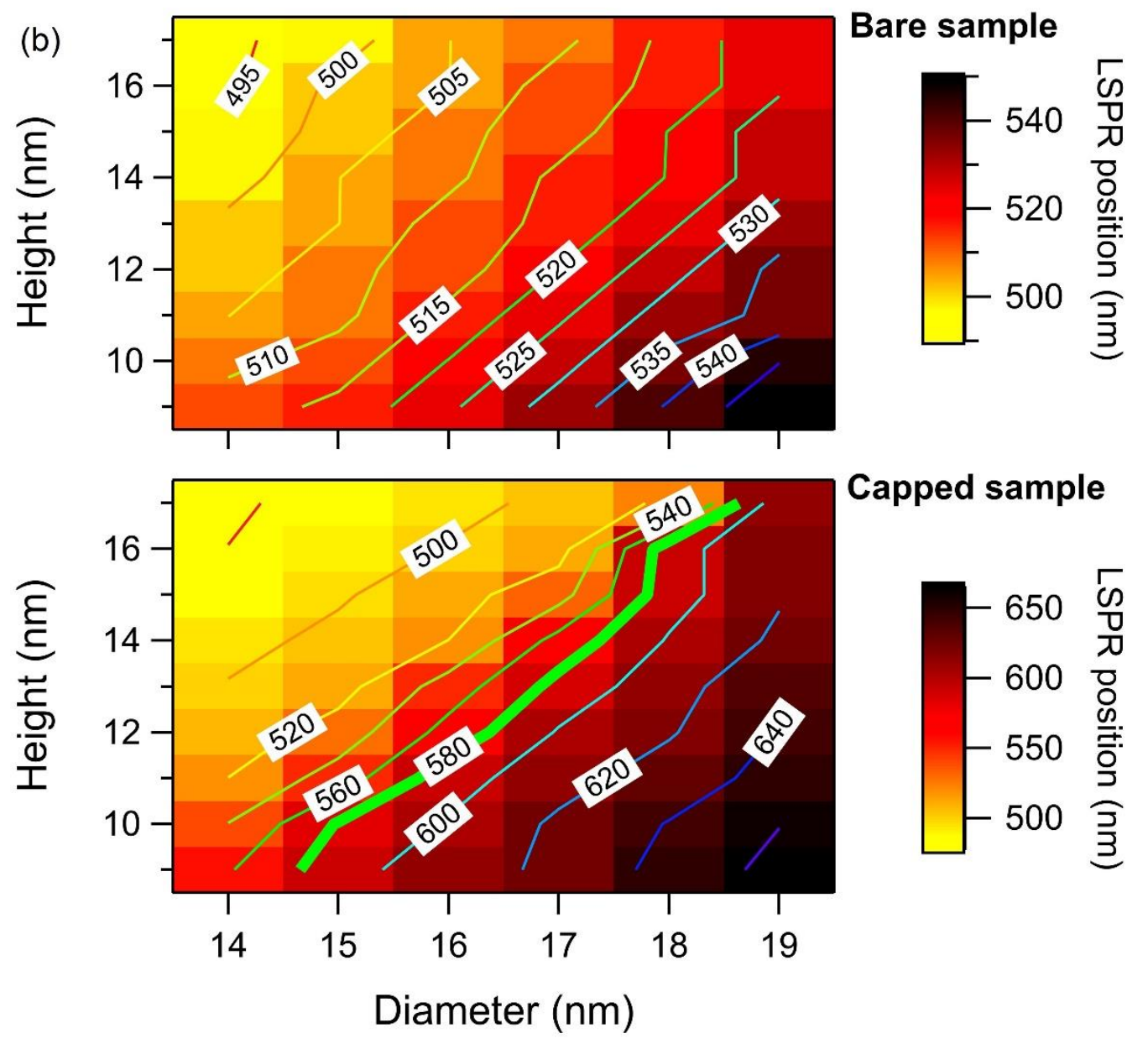


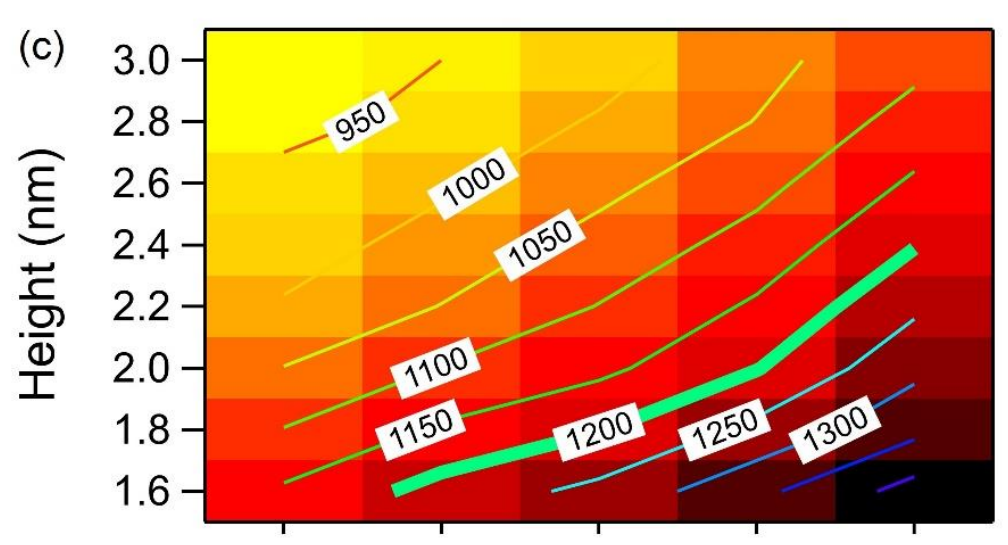

\section{Bare sample}
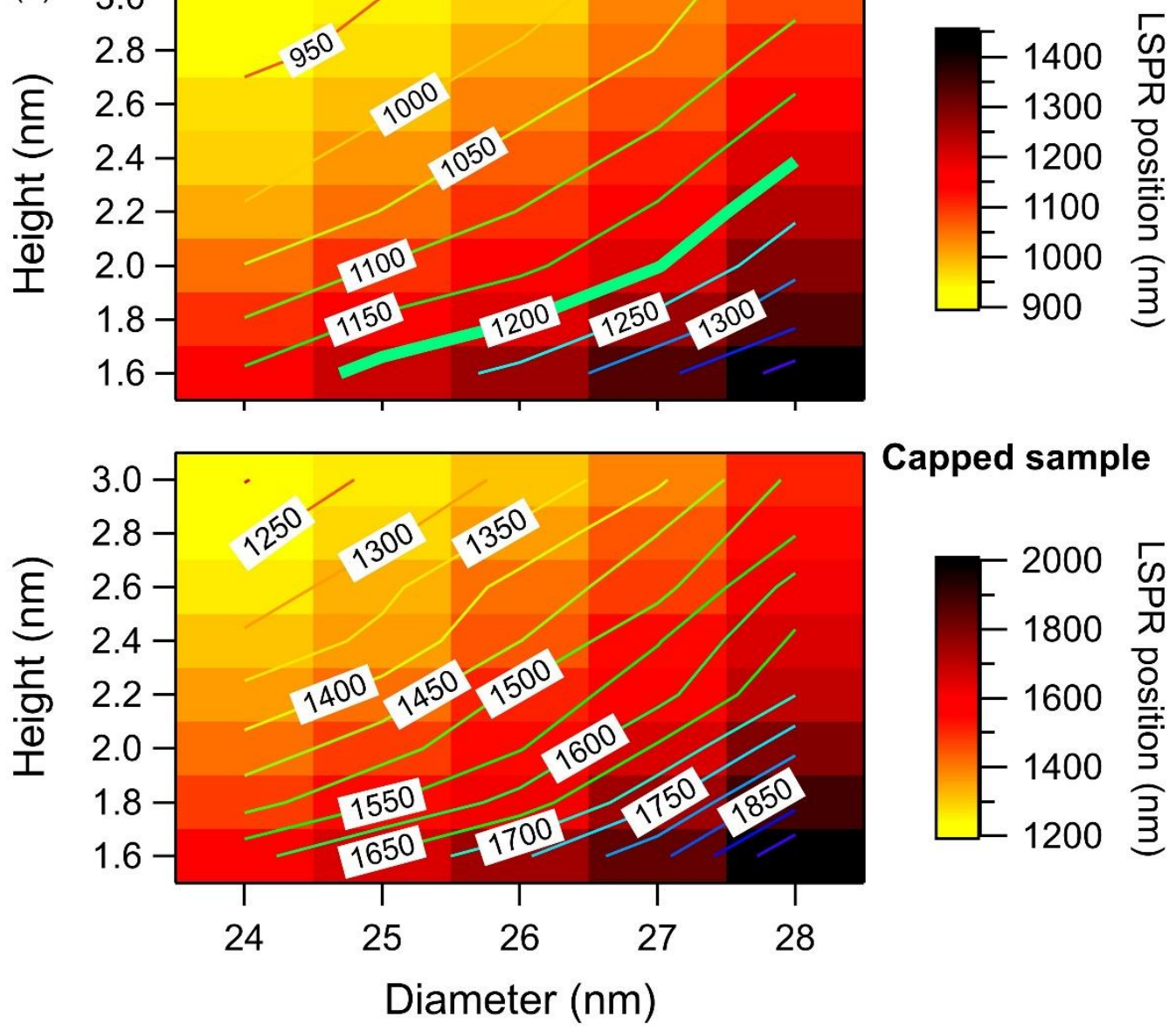

Capped sample

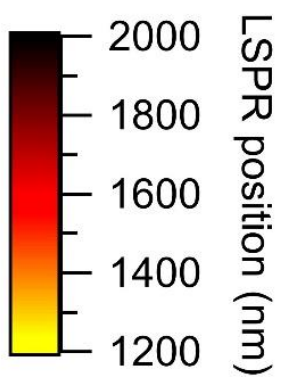

Fig. 5: (a) The geometry of the nanostructures used for the FDTD calculations. (b)

Contour plots of the wavelength of maximum absorbance for bare (upper panel) and

$\mathrm{SiN}_{\mathrm{x}}$-capped (lower panel) $\mathrm{ZrN}$ nanostructures for varying diameter (D) and height $(\mathrm{H})$.

(c) Contour plots of the wavelength of maximum absorbance for bare (upper panel) and $\mathrm{SiN}_{\mathrm{x}}$-capped (lower panel) TiN nanostructures for varying diameter (D) and height $(\mathrm{H})$. The thick green lines correspond to the experimental position. 

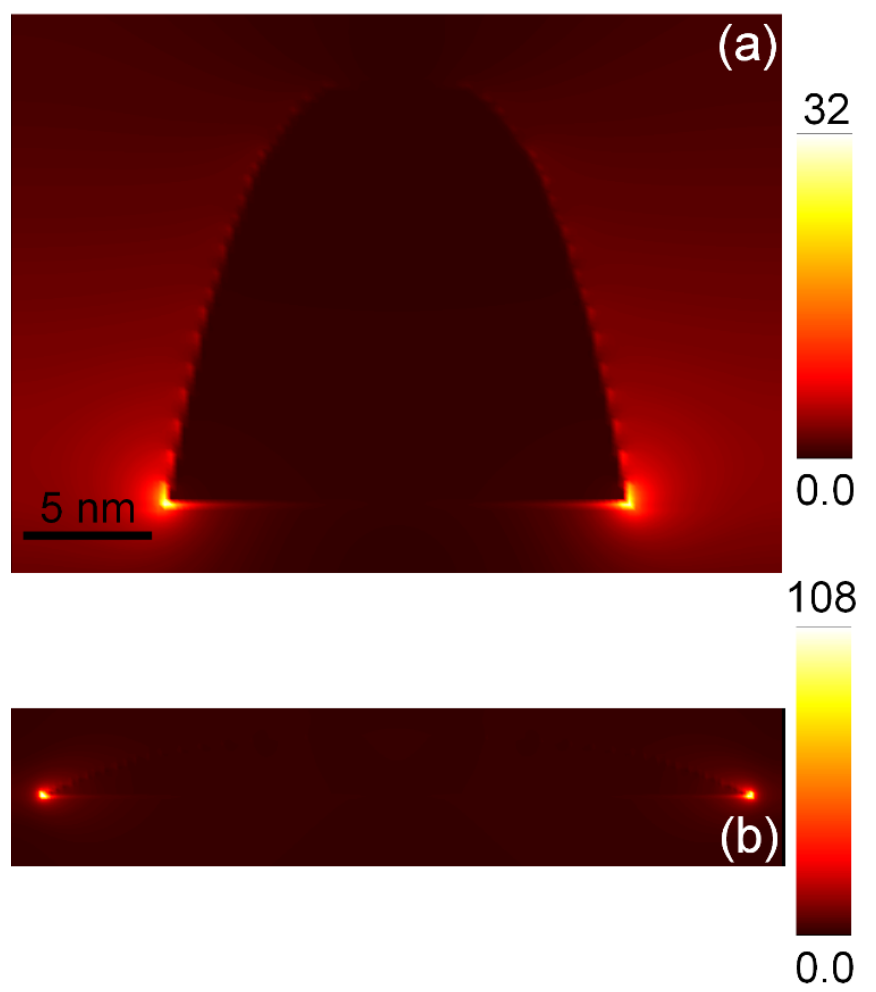

Fig. 6: Near-field enhancement distributions around bare $\mathrm{ZrN}$ (a) and $\operatorname{TiN}$ (b) nanostructures for appropriate $(H, D)$ values (see text) and laser excitation at $1030 \mathrm{~nm}$. 


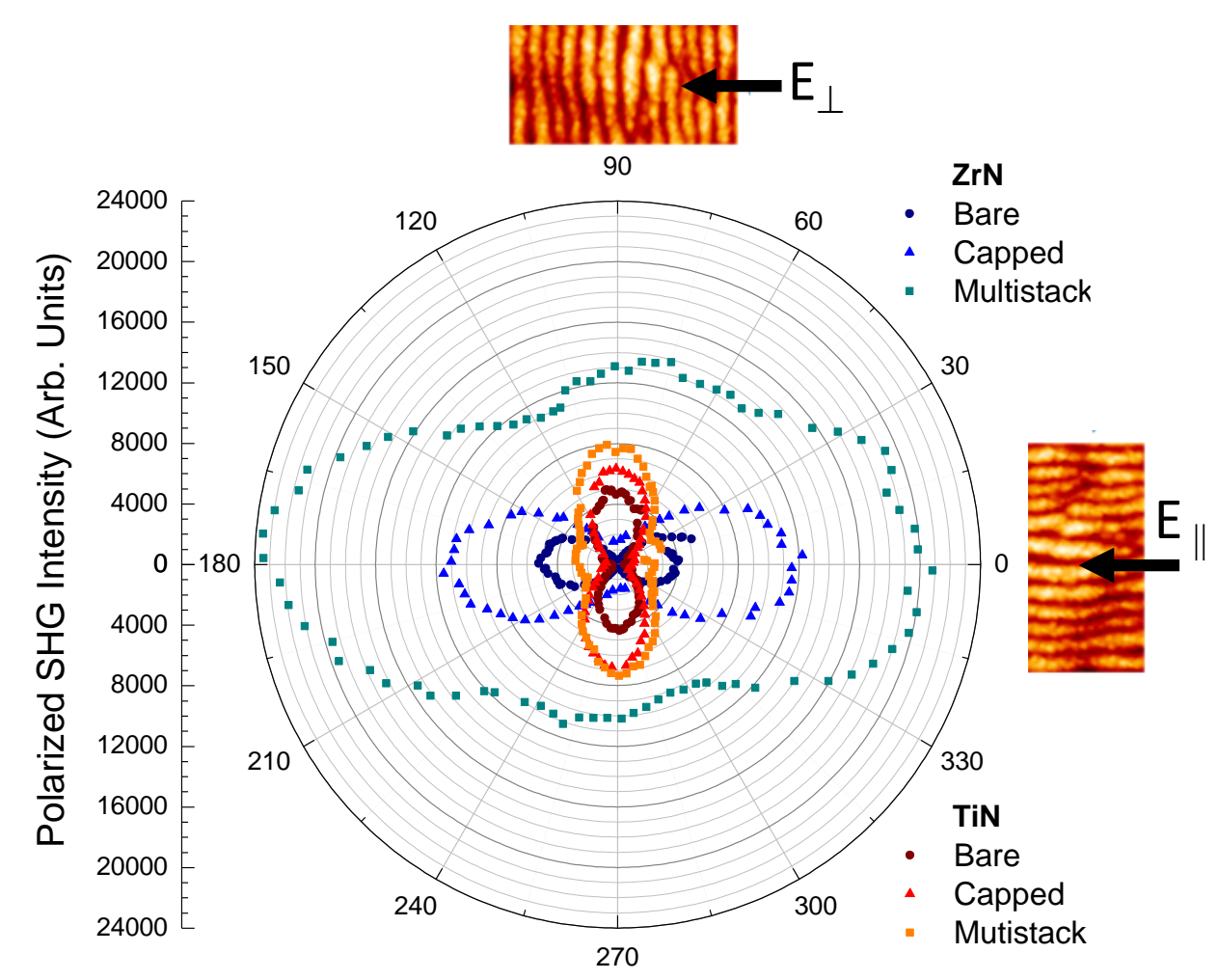

Fig. 7: Polar diagrams of polarized SHG of the $\mathrm{ZrN}$ and TiN nanostructures probed by a $1030 \mathrm{~nm}$ laser beam; at $0^{\circ}$ the electric field polarization is parallel with the ripples of the samples. 

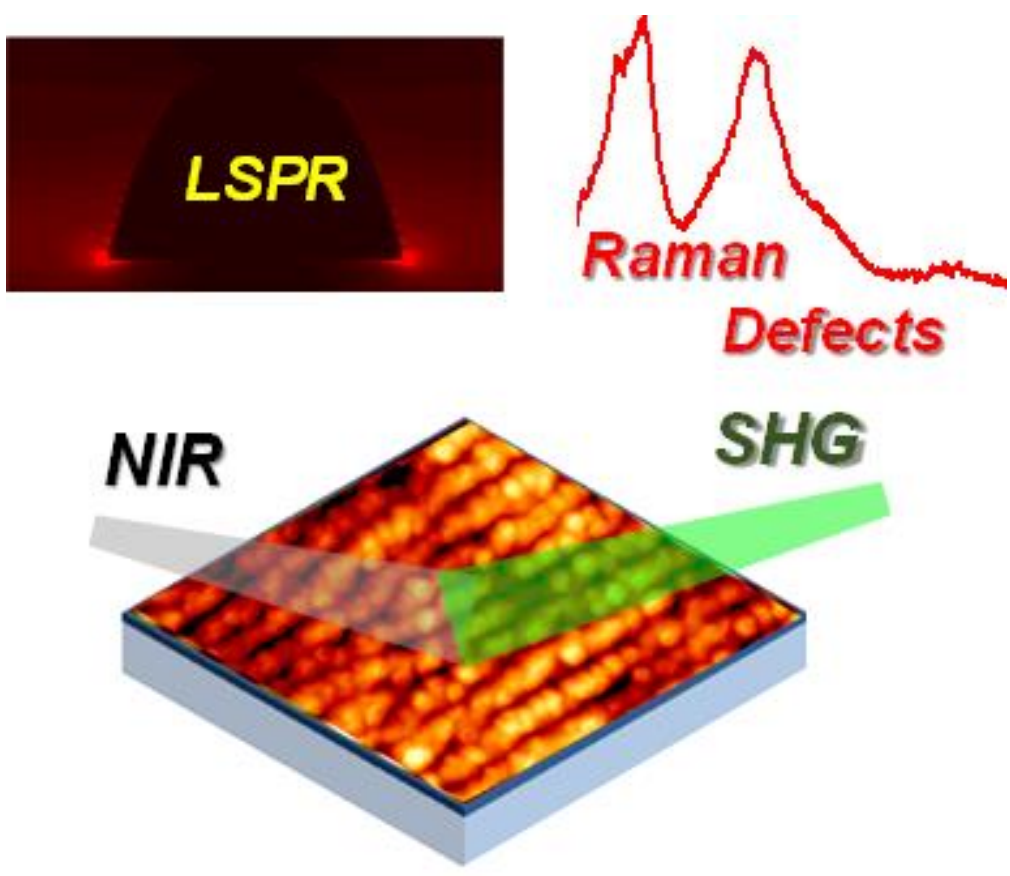

TOC Figure 


\section{ASSOCIATED CONTENT}

Supporting Information. The SI section includes:

Figure S1: Linear AFM scans

Figure S2: AFM comparison of single- and multi-layer structures

Figure S3: Optical absorbance spectra calculated by FDTD

Figure S4: The SHG data in cartesian plot

Tables S1, S2: Quantification of Raman analysis

\section{AUTHOR INFORMATION}

\section{Corresponding Author}

*Panos Patsalas, e-mail: ppats@physics.auth.gr, ORCID: orcid.org/0000-0002-28766820

\section{Author Contributions}

The manuscript was written through contributions of all authors. All authors have given approval to the final version of the manuscript.

\section{ACKNOWLEDGMENTS}

P.P. acknowledges the University of Poitiers for granting him a visiting Professor position under which part of this work was performed. This work pertains to the French Government program "Investissements d'Avenir" (LABEX INTERACTIFS, reference ANR-11-LABX-0017-01, and EUR INTREE, reference ANR-18-EURE-0010). 


\section{ABBREVIATIONS}

GLAD, glancing angle deposition

TMN, transition metal nitrides

AFM, atomic force microscopy

LSPR, localized surface plasmon resonance

FDTD, finite difference time domain

SHG, second-harmonic generation

NIR, near infrared

NW, nanowires

DIBS, dual ion beam sputtering

NFE, near field enhancement

PSHG, polarized second harmonic generation

TA, transverse acoustic

LA, longitudinal acoustic 


\section{REFERENCES}

1. Patsalas, P.; Logothetidis, S. Interface Properties and Structural Evolution of Nanoscale TiN/Si and TiN/GaN Heterostructures. Journal of Applied Physics 2003, 93, 989-998.

2. Reinholdt, A.; Pecenka, R.; Pinchuk, A.; Runte, S.; Stepanov, A.L.; Weirich, T.E.; Kreibig, U. Structural, compositional, optical and colorimetric characterization of TiN-nanoparticles. The European Physical Journal D 2004, 31, 69-76.

3. Naik G.V.; Kim J.; Boltasseva A. Oxides and nitrides as alternative plasmonic materials in the optical range. Optical Materials Express 2011, 1, 1090-1099.

4. Guler, U.; Boltasseva, A.; Shalaev, V.M. Refractory Plasmonics. Science 2014, 344, 263-264.

5. Patsalas P.; Charitidis C.; Logothetidis S. The effect of substrate temperature and biasing on the mechanical properties and structure of sputtered titanium nitride thin films. Surface and Coatings Technology 2000, 125, 335-340.

6. Abadias G.; Ivashchenko V.I.; Belliard L.; Djemia P. Structure, phase stability and elastic properties in the $\mathrm{Ti}_{1-\mathrm{x}} \mathrm{Zr}_{\mathrm{x}} \mathrm{N}$ thin-film system: Experimental and computational studies. Acta Materialia 2012, 60, 5601-5614.

7. Abadias G.; Koutsokeras L.E.; Siozios A.; Patsalas P. Stress, phase stability and oxidation resistance of ternary Ti-Me-N $(\mathrm{Me}=\mathrm{Zr}$, Ta) hard coatings. Thin Solid Films 2013, 538, 56-70.

8. Abadias G.; Kanoun M.B.; Goumri-Said S.; Koutsokeras L.; Dub S.N.; Djemia Ph. Electronic structure and mechanical properties of ternary ZrTaN alloys studied by 
ab initio calculations and thin-film growth experiments. Physical Review B 2014, 90, art. no. 144107.

9. Gui L.; Bagheri S.; Strohfeldt N.; Hentschel M.; Zgrabik C.M.; Metzger B.; Linnenbank H.; Hu E.L.; Giessen H. Nonlinear Refractory Plasmonics with Titanium Nitride Nanoantennas. Nano Letters 2016, 16, 5708-5713.

10. Sato R.; Ishii S.; Nagao T.; Naito M.; Takeda Y. Broadband Plasmon Resonance Enhanced Third-Order Optical Nonlinearity in Refractory Titanium Nitride Nanostructures. ACS Photonics 2018, 5, 3452-3458.

11. Kinsey N.; Syed A.A.; Courtwright D.; DeVault C.; Bonner C.E.; Gavrilenko V.I.; Shalaev V.M.; Hagan D.J.; Van Stryland E.W.; Boltasseva A. Effective third-order nonlinearities in metallic refractory titanium nitride thin films. Optical Materials Express 2015, 5, 2395-2403.

12. Naik G.V.; Schroeder J.L.; Ni X.; Kildishev A.V.; Sands T.D.; Boltasseva A. Titanium nitride as a plasmonic material for visible and near-infrared wavelengths. Optical Materials Express 2012, 2, 478-489.

13. Naik G.V.; Saha B.; Liu J.; Saber S.M.; Stach E.A.; Irudayaraj J.M.K.; Sands T.D.; Shalaev V.M.; Boltasseva A. Epitaxial superlattices with titanium nitride as a plasmonic component for optical hyperbolic metamaterials. Proceedings of the National Academy of Sciences of the United States of America 2014, 111, 75467551.

14. Lu Y.-J.; Sokhoyan R.; Cheng W.-H.; Kafaie Shirmanesh G.; Davoyan A.R.; Pala R.A.; Thyagarajan K.; Atwater H.A. Dynamically controlled Purcell enhancement 
of visible spontaneous emission in a gated plasmonic heterostructure. Nature Communications 2017, 8, art. no. 1631.

15. Saha S.; Dutta A.; Kinsey N.; Kildishev A.V.; Shalaev V.M.; Boltasseva A. OnChip Hybrid Photonic-Plasmonic Waveguides with Ultrathin Titanium Nitride Films. ACS Photonics 2018, 5, 4423-4431.

16. Chaudhuri K.; Shaltout A.; Shah D.; Guler U.; Dutta A.; Shalaev V.M.; Boltasseva A. Photonic Spin Hall Effect in Robust Phase Gradient Metasurfaces Utilizing Transition Metal Nitrides. ACS Photonics 2019, 6, 99-106.

17. Habib A.; Florio F.; Sundararaman R. Hot carrier dynamics in plasmonic transition metal nitrides. Journal of Optics UK 2018, 20, art. no. 064001.

18. Metaxa C.; Kassavetis S.; Pierson J.F.; Gall D.; Patsalas P. Infrared Plasmonics with Conductive Ternary Nitrides. ACS Applied Materials and Interfaces 2017, 9, 10825-10834.

19. Lalisse A.; Tessier G.; Plain J.; Baffou G. Plasmonic efficiencies of nanoparticles made of metal nitrides (TiN, ZrN) compared with gold. Scientific Reports 2016, 6, art. no. 38647 .

20. Kassavetis S.; Bellas D.V.; Abadias G.; Lidorikis E.; Patsalas P. Plasmonic spectral tunability of conductive ternary nitrides. Applied Physics Letters 2016, 108, art. no. 263110.

21. Patsalas P.; Kalfagiannis N.; Kassavetis S.; Abadias G.; Bellas D.V.; Lekka C.; Lidorikis E. Conductive nitrides: Growth principles, optical and electronic properties, and their perspectives in photonics and plasmonics. Materials Science and Engineering R: Reports 2018, 123, 1-55. 
22. Naik G.V.; Shalaev V.M.; Boltasseva A. Alternative plasmonic materials: Beyond gold and silver. Advanced Materials 2013, 25, 3264-3294.

23. Li W.; Guler U.; Kinsey N.; Naik G.V.; Boltasseva A.; Guan J.; Shalaev V.M.; Kildishev A.V. Refractory plasmonics with titanium nitride: Broadband. Advanced Materials 2014, 26, 7959-7965.

24. Briggs J.A.; Naik G.V.; Zhao Y.; Petach T.A.; Sahasrabuddhe K.; GoldhaberGordon D.; Melosh N.A.; Dionne J.A. Temperature-dependent optical properties of titanium nitride. Applied Physics Letters 2017, 110, art. no. 101901.

25. West P.R.; Ishii S.; Naik G.V.; Emani N.K.; Shalaev V.M.; Boltasseva A. Searching for better plasmonic materials. Laser and Photonics Reviews 2010, 4, 795-808.

26. Blaber M.G.; Arnold M.D.; Ford M.J. A review of the optical properties of alloys and intermetallics for plasmonics. Journal of Physics Condensed Matter 2010, 22, art. no. 143201.

27. Guler U.; Shalaev V.M.; Boltasseva A. Nanoparticle plasmonics: Going practical with transition metal nitrides. Materials Today 2015, 18, 227-237.

28. Karaballi, R.A.; Esfahani Monfared, Y.; Dasog, M. Photothermal Transduction Efficiencies of Plasmonic Group 4 Metal Nitride Nanocrystals. Langmuir 2020, 36, $5058-5064$.

29. Karaballi, R.A.; Humagain, G.; Fleischman, B.R.A.; Dasog, M. Synthesis of Plasmonic Group-4 Nitride Nanocrystals by Solid-State Metathesis. Angewandte Chemie International Edition 2019, 58, 3147-3150. 
30. Rodriguez, C.B.; Barragan, A.A.; Nava, G.; Exarhos, S.; Mangolini, L. Stabilizing the Plasmonic Response of Titanium Nitride Nanocrystals with a Silicon Oxynitride Shell: Implications for Refractory Optical Materials. ACS Applied Nano Materials 2020, 3, 4504-4511.

31. Barragan, A.A.; Ilawe, N.V.; Zhong, L.; Wong, B.M.; Mangolini, L. A NonThermal Plasma Route to Plasmonic TiN Nanoparticles. J. Physical Chemistry C 2017, 121, 4, 2316-2322

32. Matenoglou G.M.; Koutsokeras L.E.; Lekka Ch.E.; Abadias G.; Kosmidis C.; Evangelakis G.A.; Patsalas P. Structure, stability and bonding of ternary transition metal nitrides. Surface and Coatings Technology 2009, 204, 911-914.

33. Shah D.; Reddy H.; Kinsey N.; Shalaev V.M.; Boltasseva A. Optical Properties of Plasmonic Ultrathin TiN Films. Advanced Optical Materials 2017, 5, art. no. 1700065.

34. Hu; J; Ren; X.; Reed; A.N.; Reese; T.; Rhee; D.; Howe; B.; Lauhon; L.J.; Urbas; A.; Odom; T.W. Evolutionary Design and Prototyping of Single Crystalline Titanium Nitride Lattice Optics. ACS Photonics 2017, 4, 606-612.

35. Briggs J.A.; Naik G.V.; Petach T.A.; Baum B.K.; Goldhaber-Gordon D.; Dionne J.A. Fully CMOS-compatible titanium nitride nanoantennas. Applied Physics Letters 2016, 108, art. no. 51110.

36. Murai S.; Fujita K.; Daido Y.; Yasuhara R.; Kamakura R.; Tanaka K. Plasmonic arrays of titanium nitride nanoparticles fabricated from epitaxial thin films. Optics Express 2016, 24, 1143-1153. 
37. Guler U.; Ndukaife J.C.; Naik G.V.; Nnanna A.G.A.; Kildishev A.V.; Shalaev V.M.; Boltasseva A. Local heating with lithographically fabricated plasmonic titanium nitride nanoparticles. Nano Letters 2013, 13, 6078-6083.

38. Dutta A.; Kinsey N.; Saha S.; Guler U.; Shalaev V.M.; Boltasseva, A. Plasmonic interconnects using zirconium nitride, Conference on Lasers and Electro-Optics. Optical Society of America Technical Digest 2016, art. no. JW2A.86.

39. Kamakura R.; Murai S.; Fujita K.; Tanaka K. Enhanced Photoluminescence from Organic Dyes Coupled to Periodic Array of Zirconium Nitride Nanoparticles. ACS Photonics 2018, 5, 3057-3063.

40. Howell I.R.; Giroire B.; Garcia A.; Li S.; Aymonier C.; Watkins J.J. Fabrication of plasmonic TiN nanostructures by nitridation of nanoimprinted $\mathrm{TiO}_{2}$ nanoparticles. Journal of Materials Chemistry C 2018, 6, 1399-1406.

41. Bagheri S.; Zgrabik C.M.; Gissibl T.; Tittl A.; Sterl F.; Walter R.; De Zuani S.; Berrier A.; Stauden T.; Richter G.; Hu E.L.; Giessen H. Large-area fabrication of TiN nanoantenna arrays for refractory plasmonics in the midinfrared by femtosecond direct laser writing and interference lithography. Optical Materials Express 2015, 5, 2625-2633.

42. Balasubramanian K.; Khare S.V.; Gall D. Energetics of point defects in rocksalt structure transition metal nitrides: Thermodynamic reasons for deviations from stoichiometry. Acta Materialia 2018, 159, 77-88.

43. Tsetseris L.; Kalfagiannis N.; Logothetidis S.; Pantelides S.T. Trapping and release of impurities in TiN: A first-principles study. Physical Review B 2008, 78, art. no. 094111. 
44. Spengler; W.; Kaiser; R.; Christensen; A.N.; Mueller-Vogt; G. Raman scattering, superconductivity, and phonon density of states of stoichiometric and nonstoichiometric TiN. Physical Review B 1978, 17, 1095-1101.

45. Patsalas P. Zirconium nitride: A viable candidate for photonics and plasmonics?. Thin Solid Films 2019, 688, art. no. 137438.

46. Chen T.-Y.; Obermeier J.; Schumacher T.; Lin F.-C.; Huang J.-S.; Lippitz M.; Huang C.-B. Modal Symmetry Controlled Second-Harmonic Generation by Propagating Plasmons. Nano Letters 2019, 19, 6424-6428.

47. Psilodimitrakopoulos S.; Mouchliadis L. Paradisanos I.; Lemonis A.; Kioseoglou G.; Stratakis E. Ultrahigh-resolution nonlinear optical imaging of the armchair orientation in 2D transition metaldichalcogenides. Light: Science and Applications 2018, 7, art. no. 18005.

48. Camelio S.; Babonneau D.; Lantiat D.; Simonot L.; Pailloux F. Anisotropic optical properties of silver nanoparticle arrays on rippled dielectric surfaces produced by low-energy ion erosion. Physical Review B 2009, 80, art. no. 155434.

49. Babonneau D.; Camelio S.; Simonot L.; Pailloux F.; Guérin P.; Lamongie B.; Lyon O. Tunable plasmonic dichroism of Au nanoparticles self-aligned on rippled $\mathrm{Al}_{2} \mathrm{O}_{3}$ thin films. Euro Physics Letters 2011, 93, art. no. 26005.

50. Babonneau D.; Vandenhecke E.; Camelio S. Formation of nanoripples on amorphous alumina thin films during low-energy ion-beam sputtering: experiments and simulations. Physical Review B 2017, 95, art. no. 085412.

51. Kaxiras, E. Atomic and Electronic Structure of Solids. p. 198, Cambridge University Press, Cambridge (2003). 
52. Koutsokeras L.E.; Matenoglou G.M.; Patsalas P. Structure, electronic properties and electron energy loss spectra of transition metal nitride films. Thin Solid Films 2013, 528, 49-52.

53. Matenoglou G.M.; Koutsokeras L.E.; Patsalas P. Plasma energy and work function of conducting transition metal nitrides for electronic applications. Applied Physics Letters 2009, 94, art. no. 152108.

54. Anders A. A structure zone diagram including plasma-based deposition and ion etching. Thin Solid Films 2010, 518, 4087-4090.

55. Patsalas P.; Gravalidis C.; Logothetidis S. Surface kinetics and subplantation phenomena affecting the texture, morphology, stress, and growth evolution of titanium nitride films. Journal of Applied Physics 2004, 96, 6234-6246.

56. Uglov V.V.; Abadias G.; Zlotski S.V.; Saladukhin I.A.; Safronov I.V.; Shymanski V.I.; Janse van Vuuren A.; O'Connell J.; Skuratov V.; Neethling J.H., Features of microstructure of $\mathrm{ZrN}, \mathrm{Si}_{3} \mathrm{~N}_{4}$ and $\mathrm{ZrN} / \mathrm{SiN}_{\mathrm{x}}$ nanoscale films irradiated by $\mathrm{Xe}$ ions. Vасиит 2017, 143, 491-494.

57. Abadias G.; Koutsokeras L.E.; Guerin Ph.; Patsalas P. Stress Evolution in Magnetron Sputtered Ti-Zr-N and Ti-Ta-N Films Studied by In-Situ Wafer Curvature: Role of Energetic Particles. Thin Solid Films 2009, 518, 1532-1537.

58. Mareus, R.; Mastail, C.; Anğaya, F.; Brunetière, N.; Abadias, A. Study of columnar growth, texture development and wettability of reactively sputter-deposited TiN, $\mathrm{ZrN}$ and $\mathrm{HfN}$ thin films at glancing angle incidence. Surface and Coatings Technology 2020, 399, 15, art. no. 126130 
59. Kassavetis S.; Ozsdolay B.D.; Kalfagiannis N.; Habib A.; Tortai J.-H.;

Kerdsongpanya S.; Sundararaman R.; Stchakovsky M.; Bellas D.V.; Gall D.;

Patsalas P. Near-zero negative real permittivity in far ultraviolet: Extending

plasmonics and photonics with B1-MoN ${ }_{\mathrm{x}}$. J. Phys. Chem. C 2019, 123, 21120-

21129.

60. Abadias, G.; Lib, C.-H.; Belliard, L.; Hu, Q.M.; Greneche, N.; Djemia, P. Large influence of vacancies on the elastic constants of cubic epitaxial tantalum nitride layers grown by reactive magnetron sputtering. Acta Materialia 2020, 184, 254266.

61. Karl P.; Ubl M.; Hentschel M.; Flad P.; Chiao Z.-Y.; Yang J.-W.; Lu Y.-J.; Giessen H. Optical properties of niobium nitride plasmonic nanoantennas for the near- and mid-infrared spectral range. Optical Materials Express 2020, 10, 2597-2606.

62. Hillier J. A.; Camelio S.; Cranton W.; Nabok A. V.; Mellor C. J.; Koutsogeorgis D.C.; Kalfagiannis N. When Ellipsometry Works Best - A Case Study with Transparent Conductive Oxides. ACS Photonics 2020, 7, 2692-2702.

63. Kapetanovic V.; Bicket I.C.; Lazar S.; Lagos M.J.; Botton G.A. Tunable Infrared Plasmon Response of Lithographic Sn-doped Indium Oxide Nanostructures, Advanced Optical Materials 2020, 8, art. no. 2001024.

64. Sarma B.K.; Rajkumar P. Al-doped $\mathrm{ZnO}$ transparent conducting oxide with appealing electro-optical properties - Realization of indium free transparent conductors from sputtering targets with varying dopant concentrations. Materials Today Communications 2020, 23, art. no. 100870. 
65. Zhu C.; Li J.; Yang Y.; Huang J.; Lu Y.; Tan R.; Dai N.; Song W. Zn-aided defect control for ultrathin GZO films with high carrier concentration aiming at alternative plasmonic metamaterials. Physica Status Solidi A 2015, 212, 1713-1718.

66. Ngo H.D.; Chen K.; Handegård O.S.; Doan A.T.; Ngo T.D.; Dao T.D.; Ikeda N.;

Ohi A.; Nabatame T.; Nagao T. Nanoantenna structure with mid-infrared plasmonic niobium-doped titanium oxide. Micromachines 2020, 11, 1-23.

67. Liu Y.; Zhang H.; Ouyang P.; Chen W.; Wang Y.; Li Z. High electrochemical performance and phase evolution of magnetron sputtered $\mathrm{MoO}_{2}$ thin films with hierarchical structure for Li-ion battery electrodes. Journal of Materials Chemistry A 2014, 2, 4714-4721.

68. Fernandes Cauduro A.L.; Fabrim Z.E.; Ahmadpour M.; Fichtner P.F.P.; Hassing Sø.; Rubahn H.-G.; Madsen M. Tuning the optoelectronic properties of amorphous $\mathrm{MoO}_{\mathrm{x}}$ films by reactive sputtering. Applied Physics Letters 2015, 106, art. no 202101.

69. Collado V.; Martin N.; Pedrosa P.; Rauch J.-Y.; Horakova M.; Yazdi M.A.P.; Billard A. Temperature dependence of electrical resistivity in oxidized vanadium films grown by the GLAD technique. Surface and Coatings Technology 2016, 304, 476-485.

70. Okimura K.; Kubo N. Preparation of $\mathrm{VO}_{2}$ films with metal-insulator transition on sapphire and silicon substrates by inductively coupled plasma-assisted sputtering. Japanese Journal of Applied Physics Letters 2005, 44, L1150-L1153.

71. Cortie M.B.; Arnold M.D.; Keast V.J. The Quest for Zero Loss: Unconventional Materials for Plasmonics. Advanced Materials 2020, 32, art. no. 1904532. 
72. Gutiérrez Y.; Brown A.S.; Moreno F.; Losurdo M. Plasmonics beyond noble metals: Exploiting phase and compositional changes for manipulating plasmonic performance. J. Appl. Phys. 2020, 128, art. no. 080901.

73. Zhang Q.; Li X.; Ma Q.; Zhang Q.; Bai H.; Yi W.; Liu J.; Han J.; Xi G. A metallic molybdenum dioxide with high stability for surface enhanced Raman spectroscopy. Nature Communications 2017, 8, art. no. 14903.

74. Etman A.S.; Wang L.; Edström K.; Nyholm L.; Sun J. Molybdenum Oxide Nanosheets with Tunable Plasmonic Resonance: Aqueous Exfoliation Synthesis and Charge Storage Applications. Advanced Functional Materials 2019, 29, art. no. 1806699.

75. Zhan Y.; Liu Y.; Zu H.; Guo Y.; Wu S.; Yang H.; Liu Z.; Lei B.; Zhuang J.; Zhang X.; Huang D.; Hu C. Phase-controlled synthesis of molybdenum oxide nanoparticles for surface enhanced Raman scattering and photothermal therapy. Nanoscale 2018, 10, 5997-6004.

76. Kalantari Osgouei A.; Hajian H.; Khalichi B.; Serebryannikov A.E.; Ghobadi A.; Ozbay E. Active Tuning from Narrowband to Broadband Absorbers Using a Subwavelength $\mathrm{VO}_{2}$ Embedded Layer. Plasmonics 2021, in press.

77. Duan X.; White S.T.; Cui Y.; Neubrech F.; Gao Y.; Haglund R.F.; Liu N. Reconfigurable Multistate Optical Systems Enabled by $\mathrm{VO}_{2}$ Phase Transitions. ACS Photonics 2020, 7, 2958-2965.

78. Schrecongost D.; Xiang Y.; Chen J.; Ying C.; Zhang H.-T.; Yang M.; Gajurel P.; Dai W.; Engel-Herbert R.; Cen C. Rewritable Nanoplasmonics through Room- 
Temperature Phase Manipulations of Vanadium Dioxide. Nano Letters 2020, 20, 7760-7766.

79. Butakov N.A.; Valmianski I.; Lewi T.; Urban C.; Ren Z.; Mikhailovsky A.A.; Wilson S.D.; Schuller I.K.; Schuller J.A. Switchable Plasmonic-Dielectric Resonators with Metal-Insulator Transitions, ACS Photonics 2018, 5, 371-377.

80. Christensen A.N.; Dietrich O.W.; Kress W.; Teuchert W.D. Phonon anomalies in transition-metal nitrides: ZrN. Physical Review B 1979, 19, 5699-5703.

81. Gioti M.; Arvanitidis J.; Christofilos D.; Chaudhuri K.; Zorba T.; Abadias G.; Gall D.; Shalaev V.M.; Boltasseva A.; Patsalas P. Plasmonic and phononic properties of epitaxial conductive transition metal nitrides. Journal of Optics UK 2020, 22, art. no. 084001 .

82. Spengler W.; Kaiser R. First and second order Raman scattering in transition metal compounds. Solid State Communications 1976, 18, 881-884.

83. Stoehr M.; Shin C.-S.; Petrov I.; Greene J.E. Raman scattering from $\mathrm{TiN}_{\mathrm{x}}$ $(0.67 \leq \mathrm{x} \leq 1.00)$ single crystals grown on $\mathrm{MgO}(001)$. Journal of Applied Physics 2011, 110, art. no. 083503.

84. Abdallah B.; Naddaf M.; A-Kharroub M. Structural, mechanical, electrical and wetting properties of $\mathrm{ZrN}_{\mathrm{x}}$ films deposited by $\mathrm{Ar} / \mathrm{N}_{2}$ vacuum arc discharge: Effect of nitrogen partial pressure. Nuclear Instruments and Methods in Physics Research $B$ 2013, 298, 55-60.

85. Balliu E.; Andersson H.; Engholm M.; Öhlund T.; Nilsson H.-E.; Olin H. Selective laser sintering of inkjet-printed silver nanoparticle inks on paper substrates to achieve highly conductive patterns. Scientific Reports 2018, 8, art. no. 10408. 
86. Kalfagiannis N.; Siozios A.; Bellas D.V.; Toliopoulos D.; Bowen L.; Pliatsikas N.; Cranton W.M.; Kosmidis C.; Koutsogeorgis D.C.; Lidorikis E.; Patsalas P. Selective modification of nanoparticle arrays by laser-induced self-assembly (MONA-LISA): putting control into bottom-up plasmonic nanostructuring. Nanoscale 2016, 8, 8236-44.

87. Siozios A.; Kalfagiannis N.; Bellas D.V.; Bazioti C.; Dimitrakopulos G.P.; Vourlias G.; Cranton W.M.; Lidorikis E.; Koutsogeorgis D.C.; Patsalas, P. Sub-surface laser nanostructuring in stratified metal/dielectric media: a versatile platform towards flexible, durable and large scale plasmonic writing. Nanotechnology 2015, 26, art. no. 155301 .

88. Patsalas P.; Kalfagiannis N.; Kassavetis S. Optical properties and plasmonic performance of titanium nitride. Materials 2015, 8, 3128-3154.

89. Shah D.; Catellani A.; Reddy H.; Kinsey N.; Shalaev V.M.; Boltasseva A.; Calzolari A. Controlling the plasmonic properties of ultrathin TiN films at the atomic level. ACS Photonics 2018, 5, 2816-2824.

90. Hentschel M.; Dregely D.; Vogelgesang R.; Giessen H.; Liu N. Plasmonic oligomers: The role of individual particles in collective behavior. ACS Nano 2011, 5, 2042-2050.

91. Sweatlock L.A.; Maier S.A.; Atwater H.A.; Penninkhof J.J.; Polman A. Highly confined electromagnetic fields in arrays of strongly coupled Ag nanoparticles. Physical Review B 2005, 71, art. no 235408. 
92. Camelio, S.; Vandenhecke, E.; Rousselet, S.; Babonneau, D. Optimization of growth and ordering of Ag nanoparticle arrays on ripple patterned alumina surfaces for strong plasmonic coupling. Nanotechnology 2014, 25, art. no. 035706.

93. Lidorikis, E.; Egusa, S; Joannopoulos, J.D. Effective medium properties and photonic crystal superstructures of metallic nanoparticle arrays. J. Appl. Phys. 2007, 101, art. no. 54304.

94. Schedin F.; Lidorikis L.; Lombardo A.; Kravets V.G.; Geim A.K.; Grigorenko A.N.; Novoselov K.S.; Ferrari A.C. Surface-enhanced Raman spectroscopy of graphene. ACS Nano 2010, 4, 5617-5626.

95. Herzog J.B.; Knight M.W.; Li Y.; Evans K.M.; Halas N.J.; Natelson D. Dark plasmons in hot spot generation and polarization in interelectrode nanoscale junctions, Nano Letters 2013, 13, 1359-1364.

96. Matranga C.; Guyot-Sionnest P. Absolute intensity measurements of the optical second-harmonic response of metals from 0.9 to $2.5 \mathrm{eV}$. J. Chem. Phys. 2001, 115 , 9503-9512.

97. Kujala S.; Canfield B.K.; Kauranen M.; Svirko Y.; Turunen J. Multipole interference in the second-harmonic optical radiation from gold nanoparticles. Physical Review Letters 2007, 98, art. no. 167403.

98. Chen T.-Y.; Obermeier J.; Schumacher T.; Lin F.-C.; Huang J.-S.; Lippitz M.; Huang C.-B. Modal Symmetry Controlled Second-Harmonic Generation by Propagating Plasmons. Nano Letters 2019, 19, 6424-6428.

99. Capretti A.; Wang Y.; Engheta N.; Dal Negro L. Comparative Study of SecondHarmonic Generation from Epsilon-Near-Zero Indium Tin Oxide and Titanium 
Nitride Nanolayers Excited in the Near-Infrared Spectral Range. ACS Photonics 2015, 2, 1584-1591.

100. O’Brien K.; Suchowski H.; Rho J.; Salandrino A.; Kante B.; Yin X.; Zhang X. Predicting nonlinear properties of metamaterials from the linear response. Nature Materials 2015, 14, 379-383.

101. Husu H.; Siikanen R.; Mäkitalo J.; Lehtolahti J.; Laukkanen J.; Kuittinen M.; Kauranen M. Metamaterials with Tailored Nonlinear Optical Response. Nano Letters 2012, 12, 673-677.

102. Galanty M.; Shavit O.; Weissman A.; Aharon H.; Gachet D.; Segal E.; Salomon A. Second harmonic generation hotspot on a centrosymmetric smooth silver surface. Light: Science and Appl. 2018, 7, art. no. 49.

103. Wen X.; Li G.; Gu C.; Zhao J.; Wang S.; Jiang C.; Palomba S.; Martijn De Sterke C.; Xiong Q. Doubly Enhanced Second Harmonic Generation through Structural and Epsilon-near-Zero Resonances in TiN Nanostructures. ACS Photonics 2018, 5, 2087-2093.

104. Venkataramanababu S.; Nair G.; Deshpande P.; Jithin M.A.; Mohan S.; Ghosh A. Chiro-plasmonic refractory metamaterial with titanium nitride (TiN) core-shell nanohelices. Nanotechnology 2018, 29, art. no. 255203.

105. Huang J.; Wang X.; Hogan N.L.; Wu S.; Lu P.; Fan Z.; Dai Y.; Zeng B.; StarkoBowes R.; Jian J.; Wang H.; Li L.; Prasankumar R.P.; Yarotski D.; Sheldon M.; Chen H.-T.; Jacob Z.; Zhang X.; Wang H. Nanoscale Artificial Plasmonic Lattice in Self-Assembled Vertically Aligned Nitride-Metal Hybrid Metamaterials. Advanced Science 2018, 5, art. no. 1800416. 
106. Sharma D.K.; Chaubey S.K.; Vasista A.B.; Karumancheril J.J.; Tripathi R.P.N.;

Bouhelier A.; Pavan Kumar G.V. Directional second-harmonic generation controlled by sub-wavelength facets of an organic mesowire. Applied Optics 2018, 57, 5914-5922. 